ARTICLE

https://doi.org/10.1038/s41467-019-13211-4

\section{Pathways to defense metabolites and evading fruit bitterness in genus Solanum evolved through 2-oxoglutarate-dependent dioxygenases}

\author{
Pablo D. Cárdenas (1) 1,2,11,12, Prashant D. Sonawane ${ }^{1,12 \star, ~ U w e ~ H e i n i g ~}{ }^{1}$, Adam Jozwiak1, Sayantan Panda1, \\ Bekele Abebie [1] ${ }^{3}$, Yana Kazachkova (10 1, Margarita Pliner (10 ${ }^{1}$, Tamar Unger ${ }^{4}$, Dalia Wolf ${ }^{5}$, Itai Ofner ${ }^{6}$,

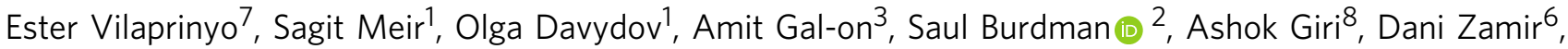 \\ Tali Scherf ${ }^{9}$, Jedrzej Szymanski ${ }^{10}$, Ilana Rogachev ${ }^{1} \&$ Asaph Aharoni ${ }^{1 *}$
}

The genus Solanum comprises three food crops (potato, tomato, and eggplant), which are consumed on daily basis worldwide and also producers of notorious anti-nutritional steroidal glycoalkaloids (SGAs). Hydroxylated SGAs (i.e. leptinines) serve as precursors for leptines that act as defenses against Colorado Potato Beetle (Leptinotarsa decemlineata Say), an important pest of potato worldwide. However, SGA hydroxylating enzymes remain unknown. Here, we discover that 2-OXOGLUTARATE-DEPENDENT-DIOXYGENASE (2-ODD) enzymes catalyze SGA-hydroxylation across various Solanum species. In contrast to cultivated potato, Solanum chacoense, a widespread wild potato species, has evolved a 2-ODD enzyme leading to the formation of leptinines. Furthermore, we find a related 2-ODD in tomato that catalyzes the hydroxylation of the bitter $\alpha$-tomatine to hydroxytomatine, the first committed step in the chemical shift towards downstream ripening-associated non-bitter SGAs (e.g. esculeoside A). This 2-ODD enzyme prevents bitterness in ripe tomato fruit consumed today which otherwise would remain unpleasant in taste and more toxic.

\footnotetext{
${ }^{1}$ Department of Plant and Environmental Sciences, Weizmann Institute of Science, Rehovot 7610001, Israel. ${ }^{2}$ Department of Plant Pathology and Microbiology and The Otto Warburg Minerva Center for Agricultural Biotechnology, The Robert H. Smith Faculty of Agriculture, Food and Environment, The Hebrew University of Jerusalem, Rehovot 7610001, Israel. ${ }^{3}$ Department of Plant Pathology and Weed Research, Agricultural Research Organization, Volcani Center, Rishon LeZion 7505101, Israel. ${ }^{4}$ Israel Structural Proteomics Centre, Weizmann Institute of Science, Rehovot 7610001, Israel. ${ }^{5}$ Department of Vegetable Research, Agricultural Research Organization, Volcani Center, Rishon LeZion 7505101, Israel. ${ }^{6}$ The Institute of Plant Sciences and Genetics in Agriculture, The Robert H. Smith Faculty of Agriculture, Food and Environment, The Hebrew University of Jerusalem, Rehovot 7610001, Israel. ${ }^{7}$ Department of Basic Medical Sciences, University of Lleida-IRBLleida, Lleida, Spain. ${ }^{8}$ Plant Molecular Biology Unit, Division of Biochemical Sciences, Council of Scientific and Industrial Research-National Chemical Laboratory, Pune 411008 Maharashtra, India. ${ }^{9}$ NMR unit, Department of Chemical Research Support, Weizmann Institute of Science, Rehovot 7610001, Israel. ${ }^{10}$ Department of Molecular Genetics, Leibniz Institute of Plant Genetics and Crop Plant Research, OT Gatersleben, Corrensstraße 3, 06466 Seeland, Germany. ${ }^{11}$ Present address: Department of Plant and Environmental Sciences, Faculty of Science, University of Copenhagen, Frederiksberg C, Denmark. ${ }^{12}$ These authors contributed equally: Pablo D. Cárdenas, Prashant D. Sonawane.

*email: prashantdsonawane@gmail.com; asaph.aharoni@weizmann.ac.il
} 
S teroidal alkaloids and their glycosylated forms (steroidal glycoalkaloids (SGAs)) are specialized metabolites produced mainly in Solanaceae plant species ${ }^{1-3}$. SGAs play a protective role against plant pathogens and predators ${ }^{2-6}$. Yet, some SGAs are considered as anti-nutritional to humans. Their effects in human's range from high toxicity (e.g. $\alpha$-solanine/ $\alpha$ chaconine in potato) to bitter tasting and unpleasant sensations (e.g. $\alpha$-tomatine in tomato) $)^{2-4,7}$. In tomato, $\alpha$-tomatine is the main SGA that accumulates in leaves and green fruits ${ }^{2,7}$. During transition from green to red fruit, $\alpha$-tomatine is converted to esculeoside A, a major non-bitter SGA (Fig. 1, and refer Supplementary Fig. 1 for detailed SGA pathway). This chemical shift during fruit ripening involves several modification steps including hydroxylation, acetylation, and glycosylation ${ }^{8,9}$. Hydroxylation of $\alpha$-tomatine to hydroxytomatine is the first proposed step in hitherto uncharacterized esculeoside A biosynthetic pathway in tomato (Fig. 1, and refer Supplementary Fig. 1 for detailed SGA pathway). Therefore, hydroxylation of $\alpha$-tomatine represents the first modification step to reduce its bitterness during tomato fruit ripening.

In cultivated potato (Solanum tuberosum), $\alpha$-chaconine and $\alpha$-solanine are the predominant SGAs (Fig. 1), and their biosynthetic route has been elucidated to a large extent ${ }^{10}$. However, in certain wild potato species, such as Solanum chacoense, $\alpha$-chaconine $/ \alpha$-solanine are hydroxylated to form leptinines (leptinine I and II) which are further acetylated to form leptines (leptine I and II) (Fig. 1). These modified SGAs are known for their insecticidal activity including against the Colorado potato beetle $(\mathrm{CPB})$, a major pest of potato and other Solanum crops comprising pepper, tomato, and eggplant ${ }^{11-18}$. New insecticides are desperately desired for $\mathrm{CPB}$ control as it lacks natural enemies and developed resistance against most chemicals. Cultivated potato varieties do not produce leptinines and leptines in any of their tissue parts. While several quantitative trait loci (QTL) regions associated with leptinine and leptine biosynthesis were identified in segregating potato populations (S. tuberosum $\times S$. chacoense), none of the genes partaking in leptinine/leptine biosynthesis have been discovered to date ${ }^{19-22}$. The formation of leptinine I and leptinine II via hydroxylation of $\alpha$-chaconine and $\alpha$-solanine, respectively, is the crucial intermediate step in the leptine biosynthetic pathway.

Notably, biosynthetic enzymes performing hydroxylation step on SGAs remain to be identified in Solanum spp. Here we identify 2-oxoglutarate-dependent dioxygenase (2-ODD) family enzymes that catalyze hydroxylation of specific SGA types in cultivated and wild Solanum species. The discovery of SGAs hydroxylating enzymes in important crops such as tomato, potato, and eggplant offers the means to reduce anti-nutritional factors, through

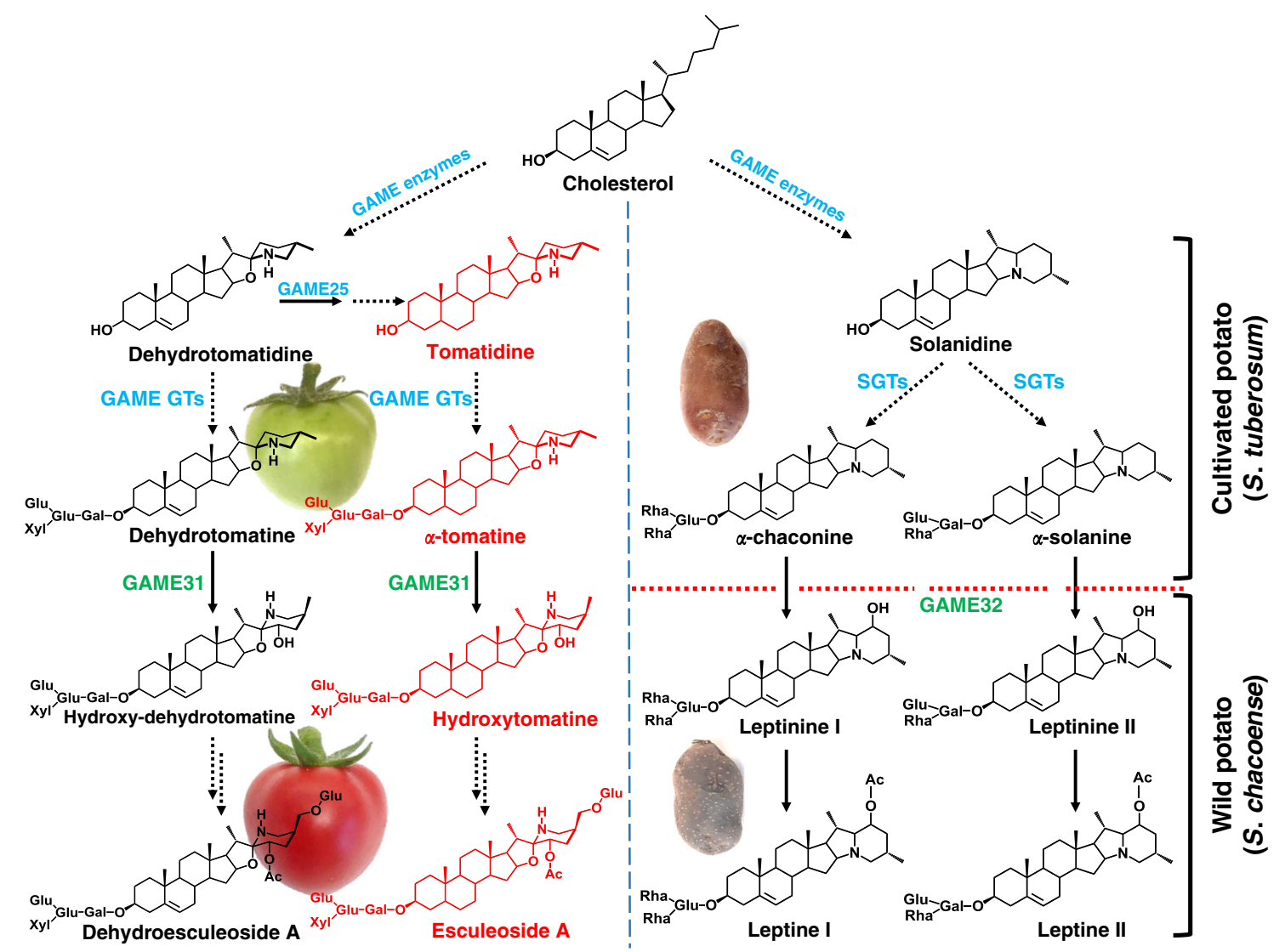

Fig. $1 \mathrm{~A}$ simplified scheme of core steroidal glycoalkaloid modification in tomato and potato species. In tomato, during transition from green to red fruit, the core $\alpha$-tomatine is bitter steroidal glycoalkaloid (SGA) and converted to the non-bitter esculeoside A and additional SGAs. The main SGAs in cultivated potato are $\alpha$-chaconine and $\alpha$-solanine. Both cultivated potato and $S$. chacoense share a common pathway up to the biosynthesis of $\alpha$-chaconine and $\alpha$-solanine. These SGAs are hydroxylated to form leptinines (leptinine I and leptinine II) and subsequently leptines (leptine I and leptine II) that are unique to the wild potato, S. chacoense. The known SGAs biosynthetic genes are shown in blue color. GAME31 and GAME32 genes characterized in this study are marked in green. Dashed and solid arrows suggest multiple or single enzymatic steps in the pathway, respectively. A detailed tomato SGAs biosynthetic pathway is presented in Supplementary Fig. 1. GAME GLYCOALKALOID METABOLISM, SGT STEROL ALKALOID GLYCOSYLTRANSFERASE, Ac Acetoxy, Glu Glucose, Gal Galactose, Xyl Xylose, Rha Rhamnose. $\alpha$-tomatine-derived SGAs are marked in red while dehydrotomatine-derived SGAs are shown in black 
genetic engineering or breeding programs, alongside protection against major pests and pathogens.

\section{Results}

Liquid chromatography-mass spectrometry (LC-MS)-based screening of SGAs in tomato introgression lines (ILs). We hypothesized that leptinines formation from $\alpha$-chaconine and $\alpha$-solanine in wild potato $S$. chacoense requires an enzyme similar to the one catalyzing hydroxylation of $\alpha$-tomatine, the major bitter $\mathrm{SGA}^{7}$ in the green tissues of related tomato species (Fig. 1). To discover the SGA hydroxylase enzyme, we implemented a QTL high-resolution mapping approach that couples profiling of selected leaf-associated SGAs with information derived from genomic bins in a tomato backcross inbred line (BIL) population $^{23}$. Including the cultivated tomato (Solanum lycopersicum $\mathrm{cv}$. M82) and wild species (Solanum pennellii) parents, the complete population set used in this study was composed of 671 lines. We analyzed the entire population by employing a leaf-dip method 24 $(n=1)$ that allows high-throughput extraction of metabolites and a rapid (10 min per sample) LC-MS method to monitor 7 different SGAs: $\alpha$-tomatine, $\alpha$-tomatine isomer, dehydrotomatine, dehydrotomatine isomer, hydroxytomatine, acetoxytomatine, and di-dehydrotomatine (Fig. 2a, b, Supplementary Figs. 2a, 3a, 4a, 5a, and $6 \mathrm{a}$, and Supplementary Data 1$)$. We noted that $\alpha$-tomatine was the most abundant SGA found in the leaves of the ILs and BILs, followed by dehydrotomatine and their respective isomers
(Supplementary Figs. 2a, 3a, 4a, 5a, and 6a). On the contrary, hydroxytomatine (Figs. 2a and 3a), acetoxytomatine (Figs. 2b and $3 \mathrm{~b}$ ), and di-dehydrotomatine (Supplementary Fig. 6a) SGA levels were low across the population, and only specific IL and BIL lines accumulated them in relatively higher amounts. Consequently, specific genomic bins associated with differential accumulation of the seven SGAs were detected (Supplementary Fig. 7). We next validated the results by analyzing grounded leaf tissue extracts $(n=3)$ of 77 core ILs, the corresponding parents (Fig. 3a, b, and Supplementary Figs. 2b, 3b, 4b, 5b, and 6b), and selected BILs covering specific SGA-associated bin regions (Fig. 2c, d). While performing the leaf-dip extraction on hundreds of BILs and ILs, we realized that, specifically in S. pennellii leaves, extraction using the leaf-dip method was not very efficient due to the waxy nature of pennellii plant leaves and thus made them less amenable for extraction. Yet, this was not a problem for all the ILs and the cultivated tomato leaves as well as in the case of ground tissue extracts of $S$. pennellii leaves.

Identification of the tomato GAME31 by QTL mapping. Five selected BILs (\#6304, \#6603, \#6664, \#6694, \#6518) linked to the accumulation of hydroxytomatine and acetoxytomatine (Fig. 2) contained introgressions overlapping with the IL2-1 line on chromosome 2 (Fig. 3c). Consequently, we focused on a mapping bin region overlapped between the IL2-1 line and the selected BILs, spanning $\sim 250 \mathrm{Kbp}$ located on chromosome 2 (Fig. $3 \mathrm{c}$ ) that
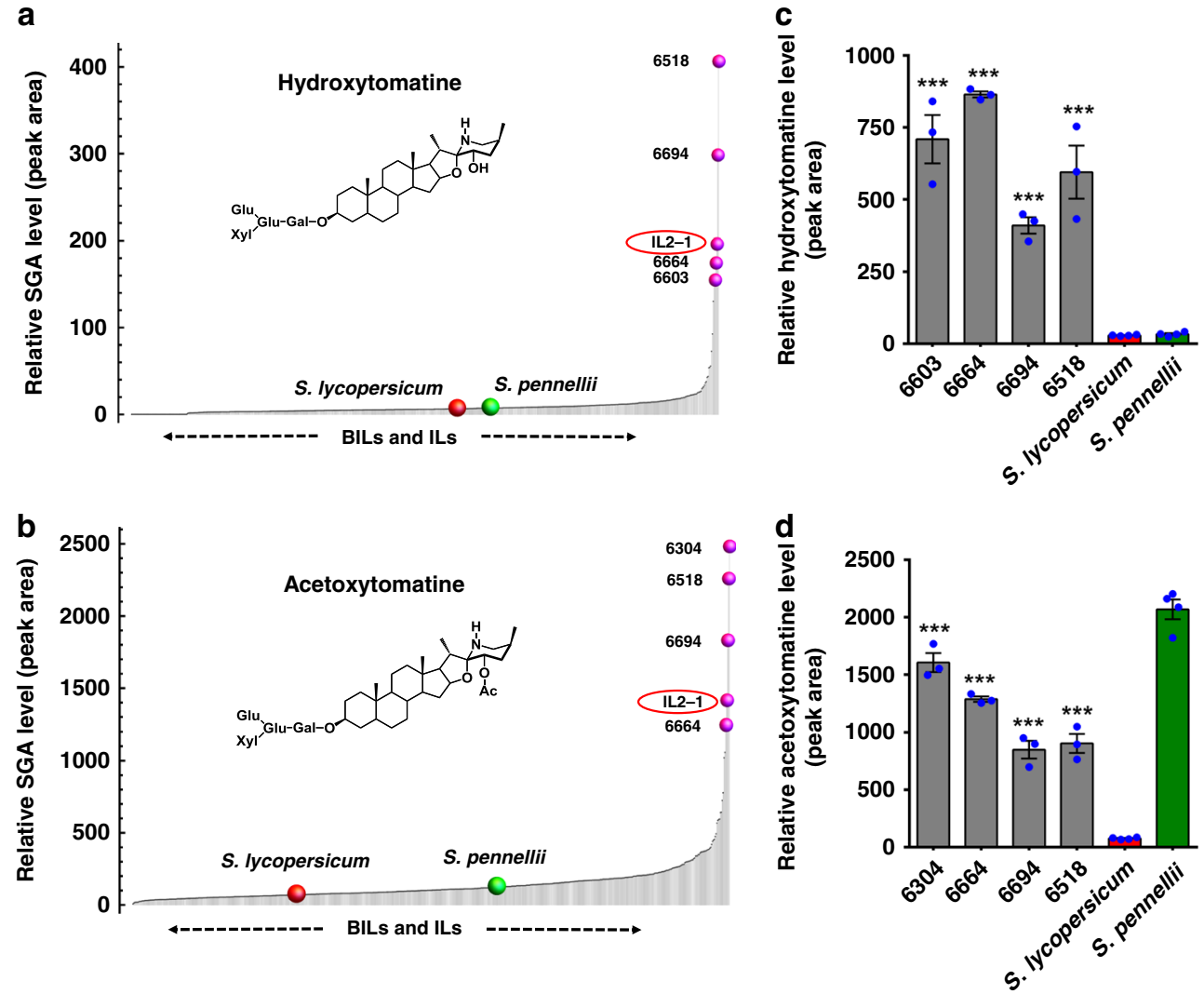

Fig. 2 LC-MS-based screening of hydroxytomatine and acetoxytomatine SGAs in the BILs and ILs. a, b Levels of hydroxytomatine (a) and acetoxytomatine (b) detected following screening of leaf tissues ( $n=1$, single replicate obtained using the leaf-dipping method) of BIL and IL population (total 671 lines). SGA levels presented in the plots were arranged in ascending order. Top five BILs/ILs showing the highest SGA content are marked by a pink spot. Refer to Supplementary Data 1 for details regarding SGA level across the BIL and IL population. c, d Validation of hydroxytomatine (c) and acetoxytomatine (d) content in extracts of ground leaf tissue from selected topmost BILs (from $\mathbf{a}$, b) along with S. lycopersicum (cv. M82) and wild species (S. pennellii) parents. Values indicate means \pm standard error mean ( $n=4$ for parental lines and $n=3$ for selected BILs and IL2-1 line). Asterisks indicate significant changes compared to S. Iycopersicum samples as calculated by Student's $t$ test ( ${ }^{\star} P$ value $<0.05 ;{ }^{\star \star} P$ value $<0.01 ;{ }^{\star \star \star} P$ value $\left.<0.001\right)$. LC-MS was used for targeted SGA profiling. The source data of Figs. $2 \mathrm{c}$ and $2 \mathrm{~d}$ are provided as a Source Data file 

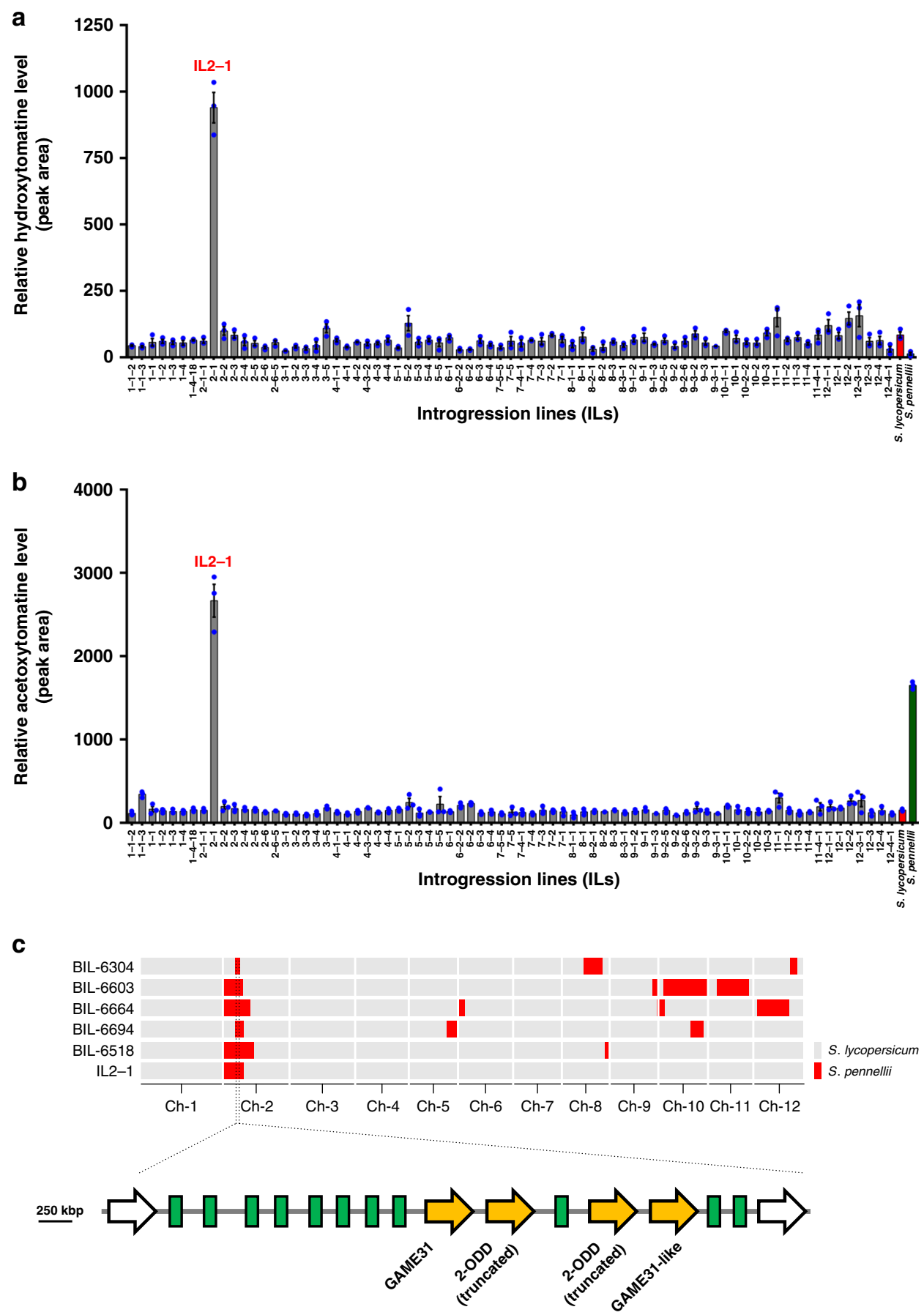

Fig. 3 Discovery of the GAME31 candidate gene in hydroxytomatine-associated QTL region on tomato chromosome 2. a, b Hydroxytomatine (a) and acetoxytomatine (b) levels in 77 core IL population including parental lines. SGA content was determined from ground leaf tissue extracts $(n=3)$. The values represent the means of three biological replicates \pm standard error mean $(n=3)$. LC-MS was used for targeted SGAs analysis. c Schematic representation of chromosomal regions in selected BILs (i.e. \#6304, \#6603, \#6664, \#6694, \#6518) and the IL2-1 line carrying introgressions from the wild species S. pennellii. An overlapping QTL (between selected BILs and IL2-1 line) region located on chromosome 2 affecting the content of hydroxytomatine and acetoxytomatine revealed 17 annotated genes. A putative candidate gene termed GAME31 belonging to the 2-oxoglutarate dependent dioxygenase (2-ODD) family is depicted with a yellow block arrow along with three other 2-ODDs in the region. The remaining 11 genes are marked in green color, while the first and last genes in the region are shown with a white block arrow. Details regarding these 17 genes are provided in Supplementary Data 2. The source data of Figs. 3a and 3b are provided as a Source Data file

represented a QTL associated with an increase in hydroxytomatine (Figs. 2a, c and 3a) and acetoxytomatine content (Figs. 2b, d and $3 \mathrm{~b})$. This bin contained 17 genes, 4 of them represented tandemly located putative 2-OXOGLUTARATE-DEPENDENT DIOXYGENASES (2-ODDs) (Fig. 3c and Supplementary Data 2).
The 2-ODD family represents one of the most versatile oxidative enzymes reported previously to catalyze hydroxylation reactions in specialized metabolism ${ }^{25}$. Two of the four 2-ODD genes were fulllength sequences and termed GLYCOALKALOID METABOLISM 31 (GAME31) and GAME31-like (Fig. 3c). It appeared that 
GAME31 is highly expressed in ripening fruit tissues (RNA-seq expression data; available at https://www.ncbi.nlm.nih.gov/ bioproject/PRJNA307656 ${ }^{26}$ as compared to leaf, petal, flower bud, and roots (Supplementary Fig. 8a) and hence significantly correlating with hydroxytomatine content during fruit development ${ }^{9}$. Thus fine metabolic QTL mapping indicated that GAME31 is possibly the enzyme carrying out the hydroxylation of $\alpha$-tomatine to form hydroxytomatine in tomato.

GAME31 gene is highly expressed in IL2-1 and selected BILs. SGA profiling in ILs and BILs showed that hydroxytomatine is a low-abundant SGA in the leaves of cultivated tomato (S. lycopersicum $c v$. M82) and wild species S. pennellii (Figs. 2a, c and 3a). Yet, all selected BILs (\#6304, \#6603, \#6664, \#6694, \#6518) carrying $S$. pennellii introgressions mapping to IL2-1 showed very high levels of hydroxytomatine in leaf tissue as compared to the parental lines (Figs. $2 \mathrm{c}$ and $3 \mathrm{a}$ ). It appeared that, out of the 17 bin genes, merely GAME31 displayed differential expression in leaves of the IL2-1 line across the core IL population (obtained from previously reported leaf transcriptome data of the IL population ${ }^{27}$ ((https://doi.org/10.5061/dryad.rm5v5); Supplementary Fig. 8b). We next compared the GAME31 expression levels in the leaves of IL2-1, selected BILs and parental lines by quantitative real-time PCR ( $\mathrm{qPCR}$ ). In cultivated tomato (cv. M82), GAME31 showed very weak expression in leaf tissue (Fig. 4a), correlating with low levels of hydroxytomatine in this genotype (Figs. $2 \mathrm{c}$ and $3 \mathrm{a}$ ). In the S. pennellii, GAME31 was highly expressed in leaves (Fig. 4a), yet this parent genotype contained very low levels of hydroxytomatine in leaves (Figs. 2c and 3a). Notably, S. pennellii leaves accumulate high levels of acetoxytomatine, the SGA derived from hydroxytomatine (Figs. 2d and $3 \mathrm{~b}$ ). Therefore, pennellii parent has most likely intense activity of the acyltransferase enzyme that acetylates hydroxytomatine, and the low hydroxytomatine levels we detected in the ground tissue extracted S. pennellii leaves in Figs. 2c and $3 \mathrm{a}$ are due to the very intense turnover of most hydroxytomatine to acetoxytomatine. In contrast, cultivated tomato (cv. M82) produces trace amount of acetoxytomatine in leaves (Figs. 2d and 3b). Thus the strong expression of GAME31 in S. pennellii likely results in higher levels of hydroxytomatine in the leaves, which are immediately being converted to the downstream acetoxytomatine SGA product. Similar to the pennellii parent, all selected BILs and IL2-1 lines displayed very high GAME31 gene expression as compared to the cultivated tomato leaves (Fig. 4a). This correlated with significantly higher hydroxytomatine content in their leaf tissue (Figs. $2 \mathrm{c}$ and 3a). Moreover, these lines also accumulate downstream acetoxytomatine in the leaves as the pennellii parental line (Figs. $2 \mathrm{~d}$ and $3 \mathrm{~b}$ ).

To investigate the molecular basis of GAME31 enhanced expression in the IL2-1 introgression, we compared GAME31 gene and protein sequences in the cultivated tomato $(c v$. M82) and $S$. pennellii genomes. The DNA alignment of both GAME31 genes shows the presence of three exons and two introns (Supplementary Fig. 9a). The three exons and second intron showed high percentage of similarity, while the first intron was different between both variants, being $\sim 4$ times longer in the S. pennellii variant (565 base pairs (bp) in S. lycopersicum vs $2594 \mathrm{bp}$ in $S$. pennellii) (Supplementary Fig. 9a). The GAME31 variants shared 96\% and 95\% homology with each other at the nucleic acid and amino acid levels, respectively (Supplementary Fig. 9b, c). Alignment of the $2000 \mathrm{bp}$ upstream genomic region showed high conservation apart from the region $\sim 400$ to $\sim 1000 \mathrm{bp}$ upstream of the transcription start site (Supplementary Fig. 10). These differences in promoter region of GAME31 between two parents might be responsible for driving the GAME31 differential expression.
GAME31 catalyzes hydroxylation of spirosolane-type SGAs. We next tested the capacity of Escherichia coli expressed recombinant GAME31 protein (from tomato) to hydroxylate SGAs and their corresponding steroidal alkaloid aglycones (SAAs) typically produced by tomato (e.g. tomatidine, $\alpha$-tomatine, and dehydrotomatine), potato (e.g., solanidine, $\alpha$-solanine, and $\alpha$-chaconine), and eggplant (e.g. solasodine and $\alpha$-solamargine). A reaction containing GAME31, $\alpha$-ketoglutarate, ascorbate, $\mathrm{Fe}^{2+}$, and $\alpha$-tomatine as a substrate produced hydroxytomatine (Fig. 4b). The hydroxytomatine peak observed here was identical to the one detected in the BIL/IL screening (Supplementary Fig. 11). Moreover, an additional two small peaks of hydroxytomatine isomers were also detected in the GAME31 enzyme assay as the commercial standard of $\alpha$-tomatine apparently contained small amount of $\alpha$-tomatine isomers as impurity (Supplementary Fig. 11). GAME31 could also catalyze the reactions forming hydroxy-dehydrotomatine, hydroxysolasodine, and hydroxy-solamargine from dehydrotomatine, solasodine, and $\alpha$-solamargine, respectively (Fig. $4 \mathrm{c}$ and Supplementary Fig. 12a, b). On the other hand, it was not active with any of the characteristic potato alkaloids, i.e. the solanidane type; $\alpha$-solanine, $\alpha$-chaconine, and solanidine. We next identified the putative homolog of tomato GAME31 in cultivated eggplant (Solanum melongena) that typically produces $\alpha$-solasonine, $\alpha$-solamargine, and minor amounts of hydroxylated products (Supplementary Fig. 13). The recombinant eggplant GAME31 enzyme showed similar substrate preference as the tomato enzyme (toward the spirosolane-type tomato and eggplant SGAs) and was likewise inactive with the solanidane-type potato alkaloids (Supplementary Fig. 14a-d). Hydroxylated metabolites (enzyme assay products) were putatively identified by comparing their retention times, elemental composition, and fragmentation pattern with those described in the literature ${ }^{8,10}$. Moreover, an additional MS-MS analysis was performed to identify the structures of the enzymatic reaction products (for detailed MS-MS analysis, see Supplementary Figs. 23-26).

Functional characterization of GAME31 in tomato. The in vivo function of GAME31 was examined by altering its expression by silencing and overexpression in tomato. Silencing GAME31 (GAME31i) in tomato by RNA interference (RNAi) and cosuppression detected in some lines constitutively expressing the tomato GAME31 (GAME31 CoSup) resulted in dramatic accumulation of $\alpha$-tomatine and dehydrotomatine. (Fig. $4 \mathrm{~d}$ and Supplementary Fig. 15a). These SGAs, typically found in minor quantities in ripe fruit ${ }^{8}$, showed up to 22 -fold increase in red ripe fruit of the silenced lines as compared to wild-type ones. Inversely, SGAs produced downstream of the $\alpha$-tomatine hydroxylation reaction step toward esculeoside A (e.g. hydroxytomatine and acetoxytomatine) were reduced substantially in the GAME31i and GAME31 CoSup ripe fruit (Supplementary Fig. 15b, see Supplementary Fig. 1 for detailed SGA pathway steps and intermediates). We observed similar trend of alterations in SGA accumulation earlier in GAME31i fruit development (Supplementary Fig. 15c, d). Leaves of GAME31-overexpressing (GAME31-Ox) tomato plants displayed $\sim 4$-fold reduction in $\alpha$ tomatine and dehydrotomatine levels and accumulated 10-45 times higher hydroxytomatine (main isomer) and its isomers, as well as acetoxytomatine, that are typically present in minor levels in this tissue (Fig. 4e, Supplementary Fig. 16a, 16b and Supplementary Fig. 1 for detailed SGA pathway). The major hydroxytomatine peak we observed here is identical to the one detected in the recombinant enzyme assays and BIL/IL screening (Supplementary Fig. 17). Moreover, hydroxytomatine isomers detected in GAME31-Ox lines were the ones observed in the selected BILs and IL2-1 (Supplementary Fig. 17). GAME31-Ox 


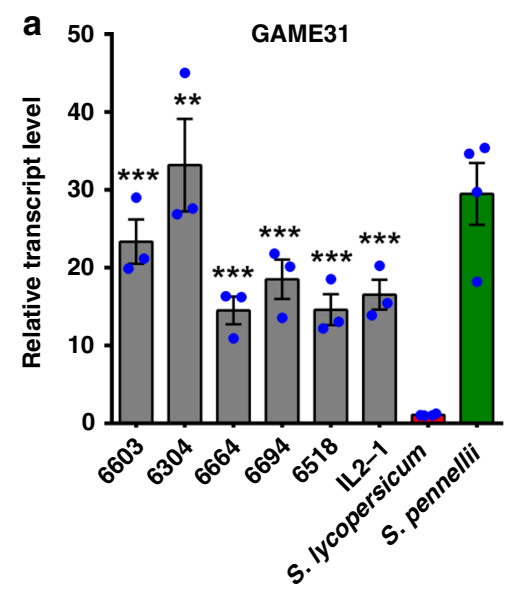

C

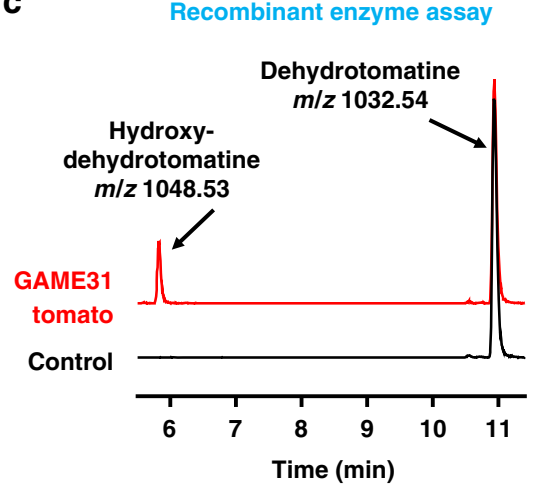

b

Recombinant enzyme assay

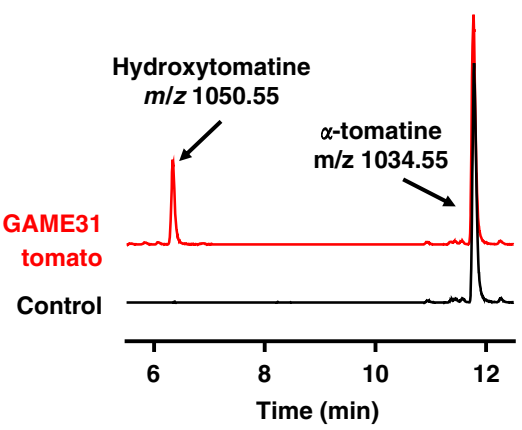

d

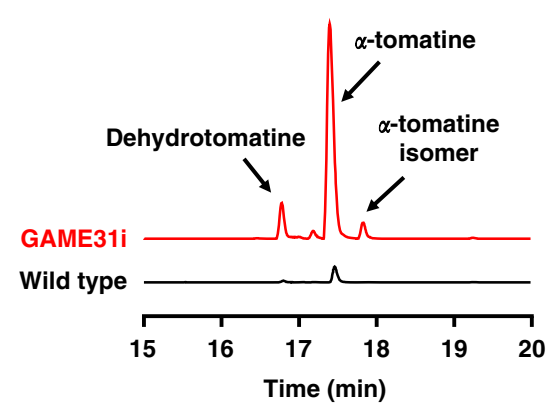

e

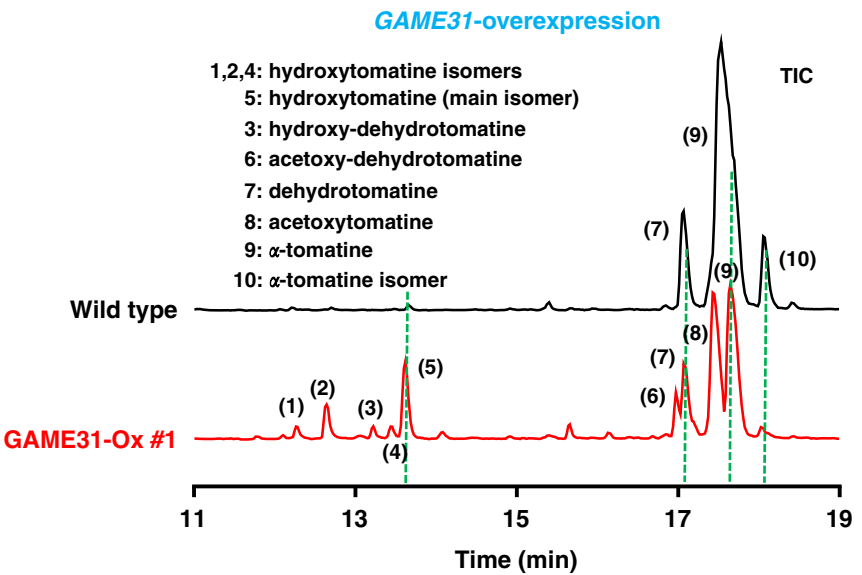

Fig. 4 GAME31 catalyzes the hydroxylation of the bitter flavor $\alpha$-tomatine in tomato fruit. a GAME31 expression levels in leaves of selected BILs, IL2-1 line, and parents [S. lycopersicum (cv. M82) and S. pennellii] as determined by quantitative real-time PCR assay. The values indicate means of three biological replicates \pm standard error mean $(n=3)$. Asterisks indicate a significant difference from $S$. lycopersicum samples calculated by Student's $t$ test ${ }^{\star} P$ value $<$ $0.05 ;{ }^{\star \star} P$ value $<0.01 ;{ }^{\star \star \star} P$ value $\left.<0.001\right)$. b, c Hydroxylation of $\alpha$-tomatine (b) and dehydrotomatine (c) by the recombinant tomato GAME31 enzyme produced in E. coli cells (marked in red). Extracted ion chromatograms were obtained by LC-MS analysis (short 17-min run). The control reaction (shown in black) was performed with the respective substrate using extracts from $E$. coli cells transformed with an empty $\mathrm{pET} 28$ vector. $\mathrm{m} / z$ is shown for each substrate and hydroxylated product. Refer to Supplementary Fig. 11 for more information on the GAME31 enzyme assay with $\alpha$-tomatine as a substrate. Details regarding the identification of enzyme assay products are provided in Supplementary Figs. 23 and 24. The structure of hydroxytomatine observed in the enzyme assay was elucidated using NMR analysis (refer to Supplementary Table 1). $\mathrm{m} / \mathrm{z}$ mass to charge, E. coli Escherichia coli. d Red, ripe fruit of GAME31-silenced plants (RNAi; GAME31i) accumulated high levels of $\alpha$-tomatine and dehydrotomatine as compared to wild-type fruit. Extracted ion chromatograms are shown. See Supplementary Fig. 15 for detailed quantitative analysis of SGAs in GAME31 RNAi and GAME31 co-suppression transgenic lines. e GAME31-overexpressing leaves (GAME31-Ox) accumulate hydroxytomatine isomers and acetoxytomatine, while these SGAs are present in minor quantities in wild-type leaves. Precursor SGAs, $\alpha$-tomatine and dehydrotomatine, were reduced substantially in GAME31-Ox lines compared to wild type. Total ion chromatograms are shown. Lines \#1 and \#2 are two independent GAME31-Ox transgenic lines (\#1 is shown here as a representative transgenic line). See Supplementary Figs. 16 and 18 for quantitative SGA analysis in GAME31-Ox transgenics with statistical information. The source data of Fig. 4a are provided as a Source Data file 
green fruit displayed reduction in $\alpha$-tomatine, $\alpha$-tomatine isomer, and dehydrotomatine levels, whereas major accumulation of hydroxytomatine and its downstream SGAs (e.g. acetoxytomatine, acetoxy-hydroxytomatine, acetoxy-dehydrotomatine) was observed as compared to wild-type green fruit (Supplementary Fig. 18a, b). In red ripe fruit of the GAME31-Ox lines, we detected increased accumulation of esculeoside $\mathrm{A}$, at the expense of $\alpha$-tomatine (Supplementary Fig. 18c). Furthermore, we detected a major increase in hydroxytomatine and its downstream SGAs in comparison to wild-type red ripe fruit (Supplementary Fig. 18c). Altering GAME31 expression (i.e. GAME31-Ox and $G A M E 31 i)$ in tomato did not affect normal growth and development of transgenic plants compared to wild-type tomato plants. The structure of major hydroxytomatine peak observed in the BILs, ILs, recombinant enzyme assays, and stable transgenic plants was unambiguously determined using nuclear magnetic resonance (NMR) analysis (Supplementary Table 1, Supplementary Figs. 33-40). Altogether, these results demonstrated that GAME31 catalyzes the hydroxylation of $\alpha$-tomatine to hydroxytomatine, the first committed step toward esculeoside $\mathrm{A}$ and related SGA formation in ripe tomato fruit.

GAME32 hydroxylates the potato SGAs to produce leptinines. Following our finding that GAME31, a 2-ODD family enzyme, was able to hydroxylate tomato and eggplant alkaloids, we continued our search for 2-ODD-type enzymes that could hydroxylate potato SGAs to form leptinines in two different wild potato $S$. chacoense accessions (i.e. 8380-1 and M6). Both leptinines and leptines are foliar-specific SGAs and therefore accumulate predominantly in leaves, stem and green floral organs as compared to stolons, roots, and tuber skin tissues of $S$. chacoense $(S c)^{28}$. Through sequence similarity search, we identified GAME31 homologs in the S. chacoense M6 genome (on unknown chromosome) and the 8380-1 accession (termed ScGAME31-M6 and ScGAME31-8380-1, respectively). These proteins share $87 \%$ and $80 \%$ homology with the tomato and eggplant GAME31 proteins, respectively. As in the case of the tomato and eggplant GAME31 proteins, both $S$. chacoense GAME31 recombinant enzymes exhibited hydroxylase activity explicitly on spirosolane-type tomato and eggplant substrates (e.g. $\alpha$-tomatine, dehydrotomatine, tomatidine, $\alpha$-solamargine, etc.) but not with the solanidane-type substrates characteristic for potato (e.g. $\alpha$-chaconine, $\alpha$-solanine, etc.) (Supplementary Figs. 19 and 20 and see Supplementary Figs. 23-27 for MS-MS analysis).

As sequence similarity was not sufficient to identify 2-ODD gene candidates associated with potato leptinine biosynthesis, we mined the publicly available $S$. chacoense M6 accession transcriptome data ${ }^{29}$ and detected two putative 2-ODD homologs showing the expression profiles correlating with the previously reported leptinine accumulation pattern in different tissues ${ }^{28}$. The corresponding proteins annotated as ScGAME32-M6 and ScGAME32-like-M6 shared 94\% homology. While ScGAME32like-M6 is located on chromosome 1, ScGAME32-M6 is assigned to scaffold_714 ( $\sim 60 \mathrm{Kbp}$ long) of an unknown chromosome along with three other 2-ODD genes (Fig. 5a). Two of the four genes in scaffold_714 appeared truncated and displayed very low expression in the transcriptome data. The full-length fourth gene (Sc2-ODD34-M6) showed comparable expression pattern to ScGAME32-M6 and ScGAME32-like-M6 genes and shared $82 \%$ homology with these two proteins. Next, we expressed ScGAME32-M6, ScGAME32-like-M6, and Sc2-ODD34-M6 proteins separately in $E$. coli and tested their activity with different SAA/SGA substrates. Incubation of the ScGAME32-M6 recombinant enzyme with $\alpha$-chaconine and $\alpha$-solanine as substrates resulted in the formation of hydroxylated products; i.e. leptinine I and leptinine II, respectively (Fig. 5b, c). An additional leptinine I isomer was also observed in the enzyme assay as $\alpha$-chaconine analytical standard contained isomer impurities (Fig. 5b). The ScGAME32-M6 enzyme was also able to produce hydroxysolanidine in vitro when incubated with solanidine, the potato steroidal alkaloid aglycone (Supplementary Fig. 21a; for MS-MS analysis, see Supplementary Fig. 28). Yet, it did not show activity with tomato and eggplant SAA/SGA substrates. Interestingly, ScGAME32-like-M6 and Sc2-ODD34-M6 did not exhibit hydroxylase activity with either $\alpha$-chaconine or $\alpha$-solanine substrates and neither with one of the tomato nor eggplant SAA/SGA substrates. Leptinines (leptinine I and II) were putatively identified by comparing their retention times, elemental composition, and fragmentation pattern with those described in the literature ${ }^{10,28}$. Moreover, an additional MS-MS analysis was performed to identify the leptinine structures (see Supplementary Figs. 29-32).

From the high leptine-producing $S$. chacoense 8380-1 accession, we isolated two isoforms of GAME32 (termed ScGAME32-8380-11 and ScGAME32-8380-1-2) and examined the corresponding recombinant enzyme activity for leptinine production. Incubation of ScGAME32-8380-1-1 or ScGAME32-8380-1-2 with $\alpha$-chaconine and $\alpha$-solanine resulted in the formation of leptinine I along with its isomer and leptinine II, respectively (Supplementary Fig. 21b-e). The S. chacoense 8380-1 accession enzymes did not show any activity with the tomato and eggplant SAA/SGA as substrates. Thus we found that ScGAME32 enzymes from the M6 and 8380-1 accessions carry out hydroxylation specifically on SGAs of the solanidane type but not on spirosolane-type substrates.

To test the in vivo activity of ScGAME32-8380-1-1 and ScGAME32-8380-1-2, we generated hairy root lines in the cultivated potato background (using Agrobacterium rhizogenesmediated transformation) (Supplementary Fig. 22a) and stable transgenic plants overexpressing them (Supplementary Fig. 22b). In transformed 5-7-week-old hairy roots overexpressing either ScGAME32-8380-1-1 or ScGAME32-8380-1-2, we detected de novo production of leptinine I isomers and leptinine II SGAs (Fig. $5 \mathrm{~d}$ and Supplementary Fig. 22c). This was accompanied by a significant reduction in $\alpha$-chaconine and $\alpha$-solanine levels (Supplementary Fig. 22c). Consistent with the hairy root results, we also observed the accumulation of leptinine I isomers and leptinine II at the expense of main SGAs in the leaves of the stable transgenic potato plants overexpressing ScGAME32-8380-1-1 or ScGAME32-8380-1-2 (Fig. 5e and Supplementary Fig. 22d). Moreover, transgenic potato plants overexpressing ScGAME32-8380-1-1 or ScGAME32-8380-12 showed normal growth and developmental phenotype compared to wild-type (non-transformed) cultivated potato.

\section{Absence of GAME32 prevents leptinines in cultivated potato.} The next question we asked was what explains the lack of leptinines/leptines in cultivated potato and their unique accumulation in the wild potato $S$. chacoense. We detected eight clustered 2-ODD genes in the cultivated potato chromosome 1 spanning a $\sim 160-\mathrm{Kbp}$ region that includes a single GAME31, one truncated GAME32like, and two 2-ODD34 homologs (Fig. 6). Four of the eight gene sequences in the cluster appeared partial. A clear homolog of the leptinines producing GAME32 gene of $S$. chacoense species is not present in cultivated potato (Fig. 6). Individual recombinant assay of the cultivated potato GAME31, GAME32-like, and the pair of 2-ODD34 enzymes did not show hydroxylase activity with $\alpha$-chaconine, $\alpha$-solanine, or with other tomato and eggplant SAA/ SGA substrates. The genomic organization of GAME31, GAME32, GAME32-like, and 2-ODD34 genes from selected Solanum species is presented in Fig. 6. The absence of the GAME32 gene in cultivated potato therefore explains the lack of leptinines and downstream leptine SGAs (Fig. 6). 
a $60 \mathrm{kbp}$

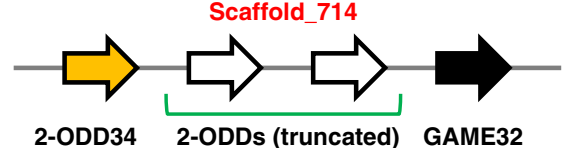

2-ODD34 2-ODDs (truncated) GAME32
Chromosome 1

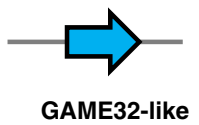

S. Chacoense

(M6 accession)

Recombinant enzyme assay

b

Recombinant enzyme assay

C

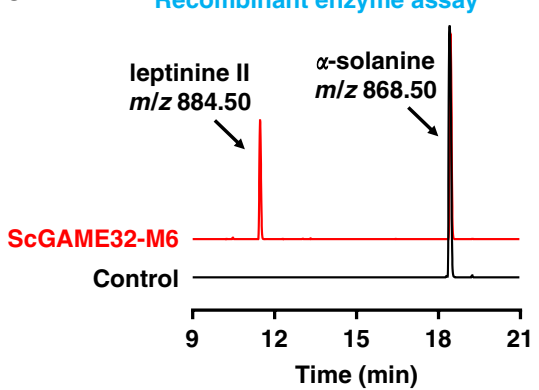

d

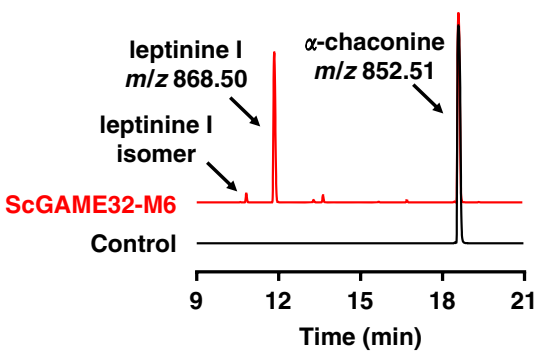

Hairy roots

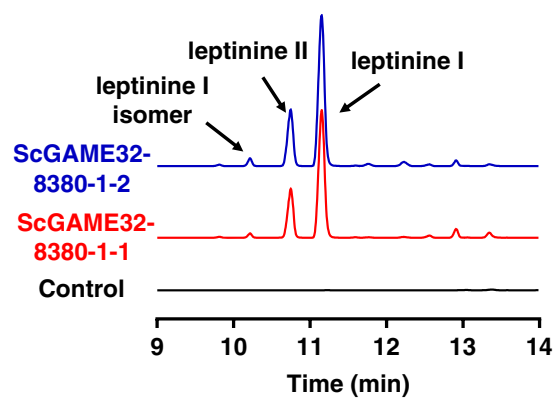

e

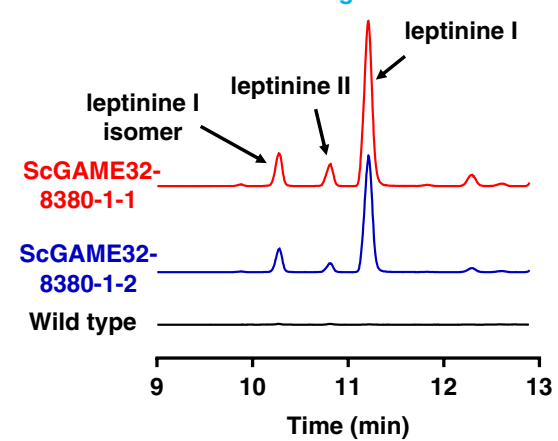

Fig. 5 GAME32 hydroxylates the main potato SGAs to form CPB resistance-associated leptinines. a Schematic presentation of the 2-ODD family members GAME32 (black), GAME32-like (blue), and 2-ODD34 (yellow) genes in the S. chacoense (Sc) genome (accession M6). Truncated 2-ODDs are shown in white block arrows. b, c The recombinant ScGAME32-M6 enzyme converts $\alpha$-chaconine (b) and $\alpha$-solanine (c) to leptinine I (plus isomer) and leptinine II, respectively. Red: reaction assay with the respective substrate and the recombinant S. chacoense-M6 GAME32 protein (produced in E. coli); black: control reaction with the respective substrate and the protein extracts of empty vector-transformed $E$. coli. Mass to charge $(\mathrm{m} / \mathrm{z})$ is shown for all substrates and assay products. MS-MS analysis and identification of leptinines metabolites are provided in Supplementary Figs. 29-32. d De novo production of leptinines in cultivated potato hairy roots overexpressing ScGAME32-8380-1-1 (in red) or ScGAME32-8380-1-2 (in blue) as compared to control (in black) hairy roots (generated with an empty vector). e SGA profiles in leaves of wild type (non-transformed) and ScGAME32-8380-1-1 or ScGAME32-8380-1-2 overexpressing stably transformed cultivated potato plants determined by LC-MS. As observed for hairy roots, accumulation of leptinines was detected in the leaves of stably transformed cultivated potato plants. Extracted ion chromatograms are presented in all cases. Refer to Supplementary Fig. 22c, d for quantitative data on SGA analysis

The sequence similarity observed in the phylogenetic analysis reflects the activity of the various 2-ODD GAME proteins reported in this study (Fig. 7a). Tomato, eggplant, and $S$. chacoense GAME31 enzymes that act on spirosolane-type SAAs/ SGAs form a separate clade. 2-ODD34 enzymes that do not partake in SGA hydroxylation form a large separated clade from the rest of the GAME31, GAME32, and GAME32-like proteins, suggesting possibly a unique divergent function for these enzymes in SGA metabolism rather than typical hydroxylation (Fig. 7a). S. chacoense GAME32 proteins that hydroxylate solanidane-type SGAs forming leptinines localize to a distinct clade and yet share a common ancestor with 2-ODD34 proteins present in all Solanum species we examined (Fig. 7a). The exclusive presence of GAME32 proteins in $S$. chacoense suggest its late independent evolution compared to 2-ODDs present in other Solanum species (e.g. GAME31 or 2-ODD34).

\section{Discussion}

SGAs including $\alpha$-tomatine are renowned defense metabolites possessing toxicity to a broad range of pathogens and predators, including bacteria, fungi, insects, oomycytes, viruses, and animals ${ }^{1-4}$. However, $\alpha$-tomatine also impacts tomato fruit flavor. Early work by Charles Rick and co-workers demonstrated a substantial association between the presence of high $\alpha$-tomatine content and bitter flavor in ripe fruit of wild cherry tomato (S. lycopersicum var. cerasiforme) accessions found in the Río Mayo valley, Peru' ${ }^{7}$. The authors suggested that a recessive, likely monogenic mutation in the enzyme catalyzing the typical degradation of $\alpha$-tomatine during fruit ripening resulted in $\alpha$-tomatine accumulation and bitterness. With similarity to tomato, metabolism of the core SGA produced in young fruit (e.g. solasodine) during ripening has been reported in other Solanum species including S. nigrum, S. sysimbrifollium, and S. mammosum ${ }^{30-32}$. The presence of high $\alpha$-tomatine (or other toxic SGAs in different Solanum species) in early stage of development protects fruit from pathogens and herbivores. In ripe tomato fruit, the entire pool of $\alpha$-tomatine is converted to non-bitter and less toxic esculeosides (Fig. 7b). This reduction in toxicity and bitterness, along with development of flavor traits (i.e. aroma, sugar, and acid content) in ripening, facilitates feeding by frugivors and consequently promotes seed dispersal. The retention of toxic and bitter alkaloids in mature ripe fruit of the bitter cerasiforme accessions was not an adaptive trait as humans have been selecting fruit with increased 

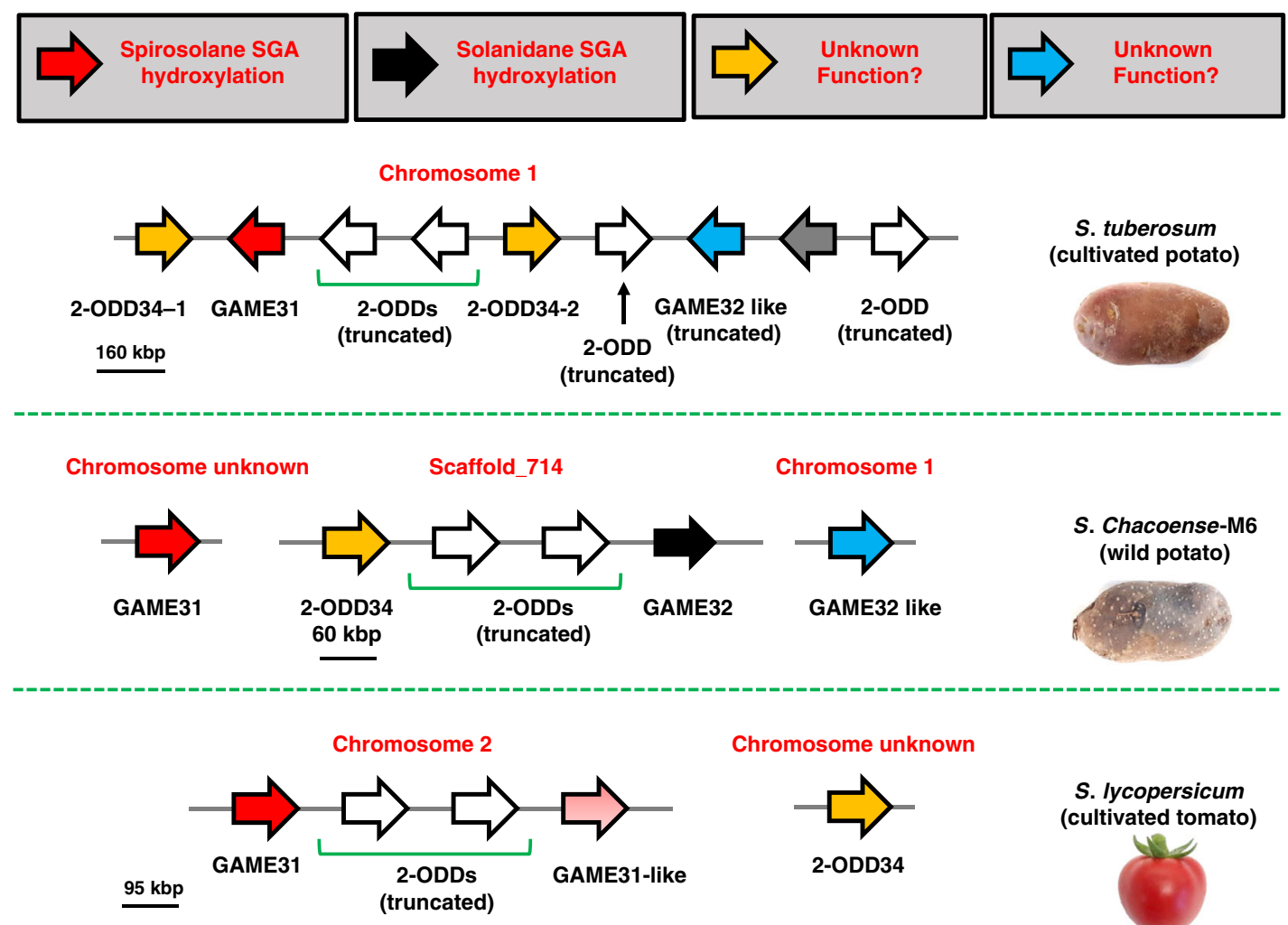

Chromosome unknown

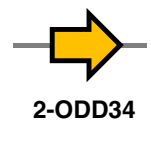

S. Iycopersicum (cultivated tomato)

(truncated)

.

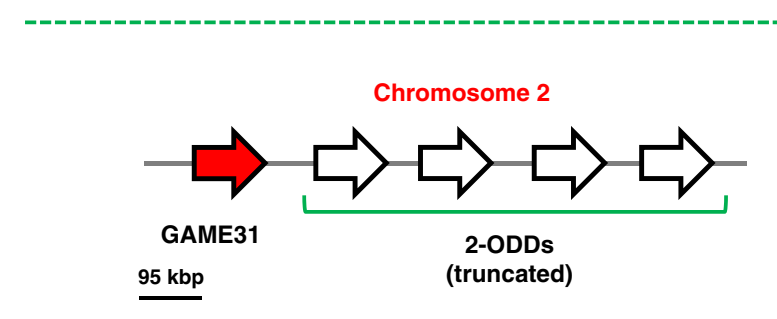

Chromosome unknown

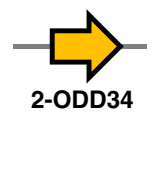

S. pennellii (wild tomato)
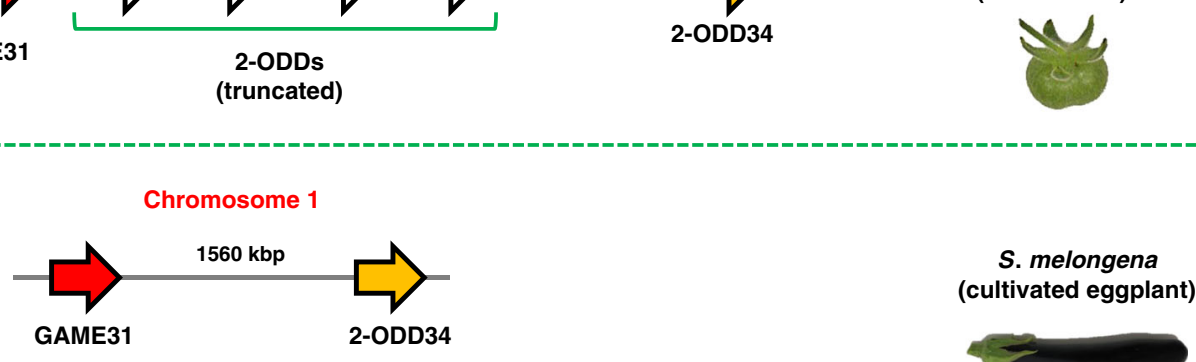

Fig. 6 Genomic organization of 2-ODD family genes in selected Solanum species associated with SGA metabolism. Four 2-ODD genes, namely, GAME31 (red block arrow), GAME32 (black block arrow), GAME32-like (blue block arrow), and 2-ODD34 (yellow block arrow), were selected for functional characterization in this study. We proposed a function for GAME31 and GAME32 genes based on in vivo and/or in vitro experiments. While GAME31 and 2-ODD34 homologs are present in all Solanum species examined, the leptinine-producing GAME32 gene appears to be unique to S. chacoense, wild potato species that possess genetic CPB pest resistance. Cultivated potato lacks the GAME32 gene, resulting in absence of leptinines and leptine SGAs, and is therefore susceptible to CPB. Truncated 2-ODDs are shown in white block arrows. The arrowheads represent direction of transcription

sweetness and reduced toxic SGA content. We therefore propose that tomato GAME31 performs the first enzymatic step in a catabolic pathway that evolved and later conserved through domestication and breeding to assure a less bitter and harmless ripe fruit as consumed at present.

CPB known as an international super-pest has become the most devastating herbivore pest of cultivated Solanum species. Despite the presence of high levels of $\alpha$-chaconine and $\alpha$-solanine, cultivated potato varieties are highly susceptible to CPB (Fig. 7b). However, the wild potato species $S$. chacoense possesses genetic resistance against CPB likely due to the presence of foliar leptinines and leptines (Fig. 7b). Long-term breeding programs in the past 30 years using high leptine $S$. chacoense genotypes failed to develop CPB-resistant cultivated potato varieties. Recently, CPB-resistant transplastomic potato plants were generated by employing an RNAi construct that targeted an essential CPB gene ${ }^{33}$. Identification of the S. chacoense GAME32 genes in this study may pave the way for alternative strategies to obtain $\mathrm{CPB}$ resistance in cultivated potato and other Solanum crops through breeding and metabolic engineering of leptinine/leptine insecticides.

\section{Methods}

Plant material. The tomato IL and BIL population were derived from crosses of the S. lycopersicum $c v$. M82 and S. pennelli ${ }^{23,34}$. The entire population set consisted 
a

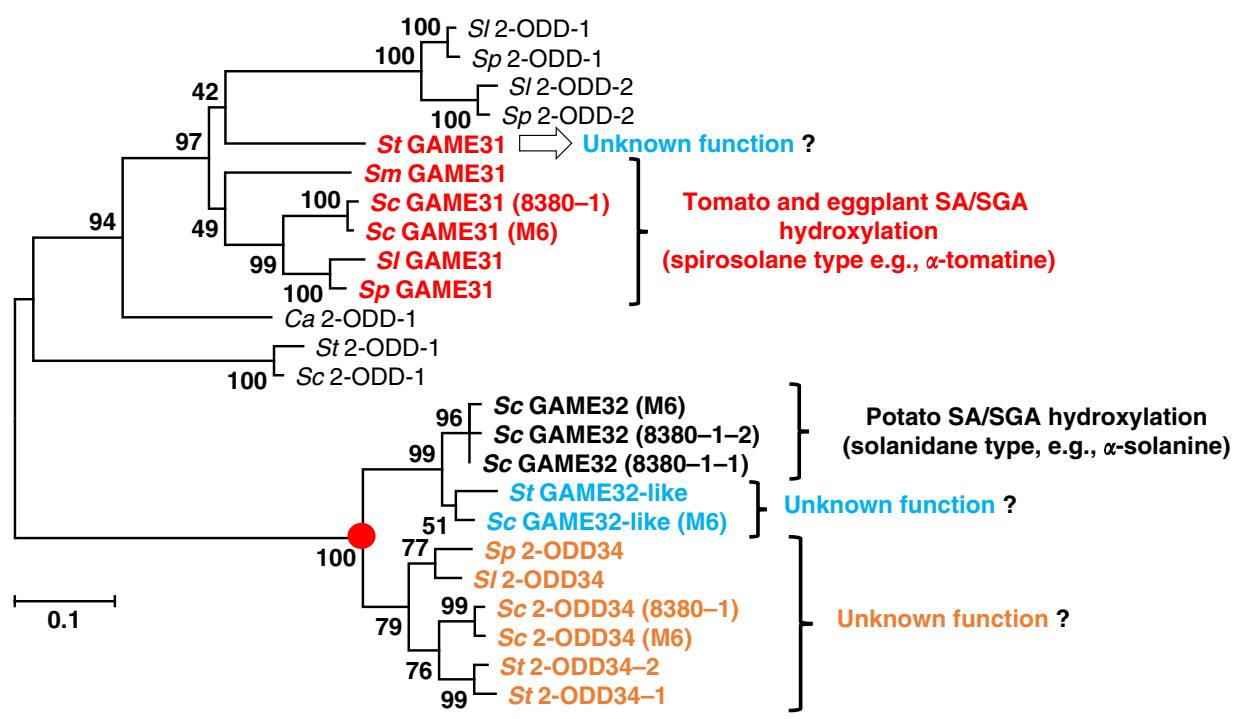

b
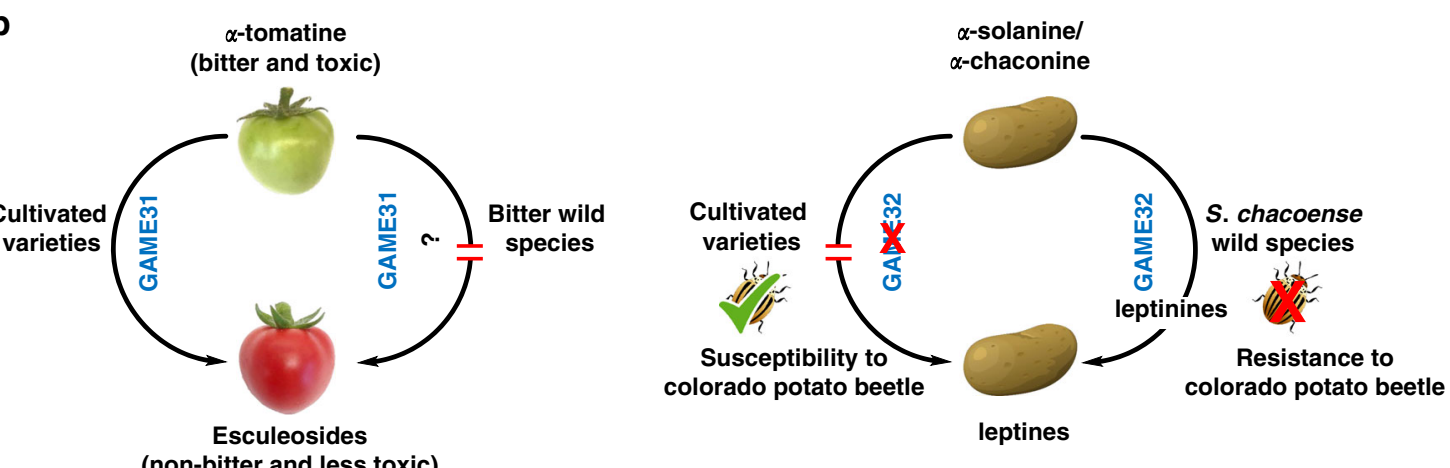

Fig. 7 Pathways to unique defense metabolites and for evading fruit bitterness evolved through 2-ODD activity. a GAME proteins (GAME31 and GAME32) carrying out typical hydroxylation reactions in Solanum SGA metabolism and other putative candidates (GAME32-like and 2-ODD34) form distinct clades in the 2-oxoglutarate-dependent dioxygenase (2-ODD) family. Sequences from the following species were represented: cultivated tomato [S. Iycopersicum, $(S I)]$, cultivated potato [S. tuberosum, (St)], wild tomato [S. pennellii, (Sp)], Capsicum annuum (Ca), cultivated eggplant [S. melongena, (Sm)], and wild potato [S. chacoense, (Sc)]. GAME31, GAME32, GAME32-like, and 2-ODD34 proteins forming separate clades are depicted in red, black, blue, and brown colors, respectively. Amino acid sequences used in the phylogenetic analysis are provided in Supplementary Data 3. Red dot denotes common ancestor shared between GAME32 and 2-ODD34 clade proteins. b A model presenting the impact of GAME31 and GAME32 proteins activity on tomato fruit flavor (bitter/ sweet) and fruit toxicity as well as resistance of potato plants to CPB insect pest. Activity of GAME31 is required to modulate bitterness and toxicity in ripe tomato fruit. Green tomato fruit accumulates a bitter and toxic $\alpha$-tomatine SGA. As the fruit matures reaching the red stage, the entire $\alpha$-tomatine pool is converted to non-bitter and less toxic esculeosides. In cultivated tomato varieties, GAME31 performs the first reaction step (i.e. hydroxylation) that ensures degradation of $\alpha$-tomatine and results in non-bitter and harmless ripe fruit. On the contrary, red ripe fruit of certain wild tomato species (e.g. S. lycopersicum var. cerasiforme) are bitter in flavor due to high accumulation of $\alpha$-tomatine ${ }^{7}$. These wild species are apparently altered in the process of $\alpha$-tomatine catabolism. GAME32 activity in S. chacoense wild potato is vital for its genetic resistance against Colorado potato beetle (CPB). Through the action of the GAME32 enzyme, $\alpha$-chaconine and $\alpha$-solanine are first converted to leptinines and further to downstream leptines, respectively, in $S$. chacoense, which makes this wild species naturally resistant to CPB. The leptinine-producing GAME32 gene is absent in the cultivated potato genome, thus preventing formation of further leptines and this likely makes cultivated potato CPB susceptible

of 671 lines, including the two parental lines M82 and S. pennellii, F1 hybrid, 132 ILs, and 536 BILs. IL and BIL population plants, tomato (S. lycopersicum cv. Micro Tom), cultivated potato (Solanum tuberosum $c v$. Desiree), and $S$ chacoense (accession M6 and 8380-1) plants were grown in a climate-controlled greenhouse at $24^{\circ} \mathrm{C}$ during the day and $18^{\circ} \mathrm{C}$ during night, with natural light. The genotyping of IL and BIL population were carried out using an Illumina $10 \mathrm{~K}$ SNP-chip ${ }^{23}$. The genotyping analysis was performed by the Trait Genetics GmbH genotyping service, according to the manufacturer's instructions. Furthermore, selected SGA profiles (in total 7 SGAs) and genotypic data of BILs and ILs were used to map the QTL regions on tomato chromosomes ${ }^{23}$.

Generation of GAME31 transgenic tomato plants. The GAME31-RNAi construct was created by introducing a 298-bp fragment (Forward oligonucleotide: GCGGCC GCATGGATTGATGTGATTATTTCACC, Reverse oligonucleotide: GGCGCGCCC TTGAAAAGATCACTTGGAGGAG) to pENTR/D-TOPO (Invitrogen) (by NotI and AscI) and further transfer of the resulting cloned fragment to the pK7GWIWG2 (II) binary vector ${ }^{35}$ using the Gateway LR Clonase II enzyme mix (Invitrogen). The
GAME31-Ox (overexpression) construct was generated using Goldenbraid cloning ${ }^{36}$ Tomato GAME31 coding sequence was initially cloned into the PUPD vector and further moved into the respective $3 \alpha 2$ and $3 \Omega 1$ vectors, which are based on the pCAMBIA backbone. Constructs were transformed into tomato ( $c v$. Micro Tom) using Agrobacterium tumefaciens (strain GV3101) mediated transformation. Briefly, cotyledon explants were excised from the 7-day-old in vitro grown tomato seedling and cut near the petiole and tip, placed on a plate containing appropriate cocultivation media, and preincubated for $24 \mathrm{~h}$ at room temperature (RT) under dark conditions. Co-cultivation of excised explants with agrobacterium $\left(\mathrm{OD}_{600}=0.3\right)$ was carried out for $48 \mathrm{~h}$ under dark conditions. After co-cultivation period, explants were transferred to shoot induction medium containing zeatin $\left(2 \mu \mathrm{g} \mathrm{ml}^{-1}\right)$, indole-3-acetic acid (IAA; $\left.0.2 \mu \mathrm{g} \mathrm{ml}^{-1}\right)$, Kanamycin $\left(50 \mu \mathrm{g} \mathrm{ml}^{-1}\right)$, and Ticarcillin $\left(250 \mu \mathrm{g} \mathrm{ml}^{-1}\right)$ for 3-4 weeks and then transferred again on shoot elongation medium containing zeatin $\left(1 \mu \mathrm{g} \mathrm{ml}^{-1}\right)$, zeatin riboside $\left(1 \mu \mathrm{g} \mathrm{ml}^{-1}\right)$, IAA $\left(0.2 \mu \mathrm{g} \mathrm{ml}^{-1}\right)$, Kanamycin $\left(50 \mu \mathrm{g} \mathrm{ml}^{-1}\right)$, and Ticarcillin $\left(100 \mu \mathrm{g} \mathrm{ml}^{-1}\right)$. Subsequently, well-developed shoots were excised and transferred to rooting medium containing indole-3-butyric acid (IBA; $2 \mu \mathrm{g} \mathrm{ml}^{-1}$ ), Kanamycin $\left(50 \mu \mathrm{g} \mathrm{ml}^{-1}\right)$, and Ticarcillin $\left(100 \mu \mathrm{g} \mathrm{ml}^{-1}\right)$. After 3-4 weeks, plantlets 
with roots were transferred to greenhouse for further analysis. Positive transgenic lines were selected by qPCR and further used for LC-MS-based metabolite analysis. Oligonucleotides used in this study are provided in Supplementary Data 4 .

\section{Generation of transgenic potato plants. ScGAME32(8380-1-1) and GAME32} (8380-1-2) coding sequences from $S$. chacoense accession 8380-1 were cloned separately into $3 \Omega 1$ vector using Goldenbraid cloning ${ }^{36}$. Constructs were transformed into cultivated potato ( $c v$. Desiree) using A. tumefaciens (strain GV3101) mediated transformation and young leaves as explants. After co-cultivation period, explants were transferred to shoot induction medium containing naphthaleneacetic acid (NAA; $\left.1 \mu \mathrm{g} \mathrm{ml}^{-1}\right)$, 6-benzyl aminopurine $\left(1 \mu \mathrm{g} \mathrm{ml}^{-1}\right)$, Kanamycin $\left(50 \mu \mathrm{g} \mathrm{ml}^{-1}\right)$, and Ticarcillin $\left(200 \mu \mathrm{g} \mathrm{ml}^{-1}\right)$ for 3-4 weeks and then transferred again on shoot elongation medium containing NAA $\left(1 \mu \mathrm{g} \mathrm{ml}^{-1}\right)$, zeatin riboside $\left(1 \mu \mathrm{g} \mathrm{ml}^{-1}\right)$, Kanamycin $\left(50 \mu \mathrm{g} \mathrm{ml}^{-1}\right)$, and Ticarcillin $\left(100 \mu \mathrm{g} \mathrm{ml}^{-1}\right)$. Subsequently, well-developed shoots were excised and transferred to rooting medium containing IBA $\left(2 \mu \mathrm{g} \mathrm{ml}^{-1}\right)$, Kanamycin $\left(50 \mu \mathrm{g} \mathrm{ml}^{-1}\right)$, and Ticarcillin $\left(100 \mu \mathrm{g} \mathrm{ml}^{-1}\right)$. After 3-4 weeks, plantlets with roots were transferred to greenhouse for further analysis. Positive transgenic lines were selected based on QPCR and further used for metabolite analysis.

Generation of transgenic potato hairy roots. Hairy roots were generated from leaves of in vitro grown cultivated potato (S. tuberosum cv. Desiree) plants infected with the A. rhizogenes strain ATCC 15834, harboring the respective gene constructs (here, ScGAME32(8380-1-1) or GAME32(8380-1-2)). From glycerol stock, the Agrobacterium cells were inoculated on agar solidified nutrient broth (NB) medium supplemented with biotin $\left(0.22 \mu \mathrm{g} \mathrm{ml}^{-1}\right)$ and incubated at $28^{\circ} \mathrm{C}$. After $48 \mathrm{~h}$ of incubation, a single colony was inoculated into $2 \mathrm{ml}$ of NB (nutrient broth) liquid medium supplemented with appropriate amount of antibiotics and biotin and cultured for $24 \mathrm{~h}$ at $200 \mathrm{rpm}, 28^{\circ} \mathrm{C}$. From the overnight culture, $200 \mu \mathrm{l}$ was inoculated into $10 \mathrm{ml} \mathrm{NB}$ supplemented with biotin and specific antibiotics. The culture was grown to $\mathrm{OD}_{600}=0.6-0.8$, pelleted at $2500 \times g$ for $10 \mathrm{~min}$ at $\mathrm{RT}$, and suspended to $\mathrm{OD}_{600}=0.5$ with MS3S (Murashige and Skoog medium $+3 \%$ sucrose) supplemented with $50 \mu \mathrm{M}$ acetosyringone and cultured for additional $1.5-2 \mathrm{~h}$ on a horizontal shaker at $200 \mathrm{rpm}$. The proximal ends of young potato leaves were removed a few $\mathrm{mm}$ above the petiole while immersed in MS3S liquid (with agrobacterium) medium, $\mathrm{pH}$ 5.8, in $90 \mathrm{~mm}$ Petri dishes, incubated for $20 \mathrm{~min}$ with occasional shaking, and blotted on sterile filter papers. About 10-15 explants were placed (the adaxial side upward) on semisolid MS3S medium in $90 \mathrm{~mm}$ Petri plates, and the plates were sealed with saran wrap and co-cultivated in the dark at $28^{\circ} \mathrm{C}$ for 2 days. After 2 days of co-cultivation, $6-8$ leaves were transferred to $90 \mathrm{~mm}$ Petri plates with semisolid MS3S medium supplemented with Kanamycin $\left(50 \mu \mathrm{g} \mathrm{ml}^{-1}\right)$, Cefotaxime $\left(500 \mu \mathrm{g} \mathrm{ml}^{-1}\right)$, and the ethylene action inhibitor, silver thiosulfate (STS, $0.2 \mathrm{mM}$ ), and incubated in light $\left(150 \mu \mathrm{mol} \mathrm{m}^{-2} \mathrm{~s}^{-1}, 16 \mathrm{~h}\right)$ at $25{ }^{\circ} \mathrm{C}$. The leaves were transferred to fresh medium every 15 days and individual roots (2-3-cm long) that appeared after 20-25 days of incubation were excised and transferred to $1 / 2 \mathrm{MS}+1.5 \%$ sucrose medium supplemented with Kanamycin $\left(50 \mu \mathrm{g} \mathrm{ml}^{-1}\right)$ and Cefotaxime $\left(300 \mu \mathrm{g} \mathrm{ml}^{-1}\right)$ for selection. Roots that grew on the selection medium were transferred to $20 \mathrm{ml} 1 / 2 \mathrm{MS}+1.5 \%$ sucrose liquid medium, with antibiotics, in 125-ml Erlenmeyer flasks and incubated in the dark on a horizontal shaker (90 rpm). After 1-2 weeks in liquid medium, hairy roots were harvested, washed with water, subsequently frozen, and ground in liquid $\mathrm{N}_{2}$. Positive hairy root transgenic lines $(n=3,3$ independent transgenic hairy root lines for each gene construct) were selected by qPCR. Furthermore, $100 \mathrm{mg}$ tissue from positive lines $(n=3)$ was used for LC-MS-based SGA measurements as described below.

Analytical standards. Analytical standards including tomatidine (Sigma-Aldrich, contains dehydrotomatidine as impurity), solanidine (ChemFaces), solasodine (ChemFaces), $\alpha$-tomatine (Carbosynth USA, contains dehydrotomatine as impurity), $\alpha$-solanine (ChemFaces), $\alpha$-chaconine (ChemFaces), and $\alpha$-solamargine (ChemFaces) were dissolved in methanol at a concentration of $1 \mathrm{mg} \mathrm{ml}^{-1}$.

Screening of SGAs in the tomato IL and BIL populations. To screen for SGAs, we developed a rapid extraction method and a short 10-min run in the ultraperformance liquid chromatography (UPLC)-quad time of flight (qTOF)-MS (Xevo, Waters), based on Schilmiller et al. ${ }^{24}$. For extraction, we selected the leaflet next to the youngest leaf (about $\sim 1$-month-old plants). The leaflet was dipped in $1 \mathrm{ml}$ of isopropanol:acetonitrile:water $(3: 3: 2 \mathrm{v} / \mathrm{v})$ containing $0.1 \%$ formic acid (in a 2-ml Eppendorf tube) and gently rocked for $1 \mathrm{~min}$. The solvent mix was then transferred to a vial for injection to the LC-MS. The leaflets were dried in an oven to obtain their weight (mg). Data from UPLC-qTOF-MS analyses was manually inspected in order to determine the major SGA metabolites present in the population. $\alpha$-tomatine and dehydrotomatine SGAs were identified using authentic standard compounds (see the "Analytical standards" section above) by comparison of their retention times and mass fragments. For other SGAs $(\alpha$-tomatine isomer, dehydrotomatine isomer, di-dehydrotomatine, acetoxytomatine, and hydroxytomatine), elemental composition and MS-MS fragmentation patterns were compared with those described in literature for their putative identification ${ }^{8}$. Peak area quantification was performed using the program TargetLynx (Waters). The resulting values were normalized to dry leaf weight and considered to be the amount of metabolite present in each sample. For ground tissue, preparation of plant extracts and metabolite analysis by UPLC-qTOF-MS was carried out as follows: Briefly, tomato plant tissues were frozen in liquid nitrogen and ground to a fine powder using an analytical mill or mortar/pestle. Then frozen tissue $(100 \mathrm{mg})$ was extracted with $80 \%$ methanol containing $0.1 \%$ formic acid [the solid:liquid ratio was kept at 1:3(w/v)]. The mixture was vortexed for $30 \mathrm{~s}$, sonicated for $30 \mathrm{~min}$ at RT, vortexed again for $30 \mathrm{~s}$, centrifuged $(13,000 \times \mathrm{g}, 10 \mathrm{~min})$, and filtered through a $0.22-\mu \mathrm{m}$ polytetrafluoroethylene membrane filter. Targeted metabolite analysis was performed using the TargetLynx program (Waters).

Plant extract preparation and targeted profiling of SGAs. Preparation of extracts and the profiling of SGAs in various tomato tissues (leaves, green, and red fruit), potato leaves, and potato hairy roots were performed with the same methods described in literature ${ }^{6,8}$. Three biological replicates $(n \geq 3)$ from each genotype were used for metabolite analysis (e.g. \#1, \#2, and \#3 are three independent GAME31-CoSup transgenic lines, and each transgenic line represents three biological samples collected from three different plants). SGA metabolites were identified by comparing the retention time and mass spectra of authentic standards analyzed on the same instrument (see the "Analytical standards" section above). When the corresponding standards were not available, SGA metabolites were putatively identified by comparing their retention times, elemental composition, and fragmentation pattern with those described in the literature $8,10,28,37$. For leptinine identification, two additional MS-MS analysis with a collision energy ramp from 20 to $80 \mathrm{eV}$ and $120 \mathrm{eV}$ (without ramp) was performed and the fragments were assigned by applying the fragmentation rules for steroid-based compounds $^{28,38}$. Relative quantification of the steroidal glycoalkaloid metabolites was carried out using the TargetLynx (Waters) program.

Quantitative real-time PCR. Gene expression analysis was performed with three biological replicates $(n \geq 3)$ for each genotype. RNA isolation was performed by the Trizol method (Sigma-Aldrich). DNase I (Sigma-Aldrich)-treated RNA was reverse transcribed using a High-capacity cDNA Reverse Transcription Kit (Applied Biosystems). Gene-specific oligonucleotides were designed with the Primer Express 2 software (Applied Biosystems). The TIP41 and NAC gene $8,26,39$ were used as reference genes for tomato and potato respectively, in qPCR analysis.

GAME31 expression in E. coli and protein purification. GAME31 genes from tomato and eggplant were cloned separately into the pET28 vector by restriction free (RF) cloning using the same methods described in literature ${ }^{40}$. The oligonucleotides used for RF cloning are provided in Supplementary Data 4. The resulting plasmids were verified by sequencing and transformed to E. coli BL21 (DE3). For isolation of the GAME31-His-tagged protein, fresh overnight cultures were diluted 1:100 in $1000 \mathrm{ml}$ of LB medium with $50 \mu \mathrm{g} \mathrm{ml}^{-1}$ kanamycin and incubated at $37^{\circ} \mathrm{C}$ and $250 \mathrm{rpm}$ until an $\mathrm{OD}_{600 \mathrm{~nm}}$ of 0.5 was reached. Subsequently, for induction of expression of the recombinant proteins, isopropyl $\beta$-D-1-thiogalactopyranoside (IPTG) was added to a final concentration of $0.2 \mu \mathrm{M}$ and the incubation was continued overnight at $15^{\circ} \mathrm{C}$ and $250 \mathrm{rpm}$. Cells were harvested by centrifugation at $6000 \times g$ and bacteria were lysed by sonication in a buffer ( $\mathrm{pH}$ 7.4) containing $0.02 \mathrm{M} \mathrm{NaH}_{2} \mathrm{PO}_{4}, 0.5 \mathrm{M} \mathrm{NaCl}$, SIGMAFAST protease inhibitor tablets (SigmaAldrich), and benzonase nuclease (Sigma-Aldrich) according to the manufacturer's instructions. Lysed cultures were centrifuged and the soluble fraction was purified by nickel affinity chromatography, which was operated with an AKTA liquid chromatography system (AKTA avant, GE Healthcare) according to the manufacturer's instructions. Protein concentration was measured using the Bio-Rad protein assay by comparison to a BSA standard, and protein aliquots were stored at $-80^{\circ} \mathrm{C}$ until further analysis.

Recombinant GAME31 enzyme assays. The steroidal alkaloid aglycones tomatidine, dehydrotomatidine, solanidine, and solasodine, as well as their glycosylated forms (i.e. SGAs) $\alpha$-tomatine, dehydrotomatine, $\alpha$-solanine, $\alpha$-chaconine, and $\alpha$ solamargine, were used as substrates in recombinant GAME31 enzyme assays. The recombinant GAME31 enzyme activity assay was performed according to Kawai et al. ${ }^{41}$ with minor modifications. Briefly, the standard full reaction $(100 \mu \mathrm{l})$ consisted of $10 \mathrm{mM} \mathrm{L}$-ascorbic acid, $10 \mathrm{mM} \alpha$-ketoglutaric acid, $500 \mu \mathrm{M} \mathrm{FeSO}, 5 \mu \mathrm{g}$ substrate, $50 \mathrm{mM}$ potassium phosphate buffer ( $\mathrm{pH}$ 7.5), and purified enzyme. All the reaction components, except the enzyme, were preincubated for $10 \mathrm{~min}$ at $30^{\circ} \mathrm{C}$, after which the reaction was started by addition of the enzyme. After incubation at $30^{\circ} \mathrm{C}$ for $3 \mathrm{~h}$, the reaction was stopped by freezing in liquid nitrogen Finally, the reaction was mixed with $250 \mu \mathrm{l}$ methanol, extracted, and analyzed by UPLC-qTOF-MS using shorter (17 min) linear gradient with conditions: For steroidal aglycone substrates (e.g. tomatidine and solasodine), from $80 \%$ to $66 \%$ phase $\mathrm{A}$ over $13 \mathrm{~min}$, from $66 \%$ to $0 \%$ phase $\mathrm{A}$ over $0.5 \mathrm{~min}$, then held at $100 \%$ phase $\mathrm{B}$ for $1.5 \mathrm{~min}$, and then returned to the initial conditions ( $80 \%$ phase A) within $0.5 \mathrm{~min}$ and conditioning at $80 \%$ phase A for $1.5 \mathrm{~min}$; for steroidal glycoalkaloid substrates (e.g. $\alpha$-tomatine and $\alpha$-solamargine), from $90 \%$ to $77 \%$ phase A over $13 \mathrm{~min}$, from $77 \%$ to $0 \%$ phase $\mathrm{A}$ over $0.5 \mathrm{~min}$, then held at $100 \%$ phase $\mathrm{B}$ for $1.5 \mathrm{~min}$, and then returned to the initial conditions ( $90 \%$ phase A) within $0.5 \mathrm{~min}$ and conditioning at $90 \%$ phase A for $1.5 \mathrm{~min}$. The mobile phase consisted of $0.1 \%$ formic acid in acetonitrile:water $(5: 95, \mathrm{v} / \mathrm{v}$; phase $\mathrm{A})$ and $0.1 \%$ formic acid 
in acetonitrile (phase B). The flow rate was $0.3 \mathrm{ml} \mathrm{min}^{-1}$, and the column temperature was kept at $35^{\circ} \mathrm{C}$. Enzyme assay products (hydroxylated compounds) were identified based on accurate mass-derived elemental composition and MS-MS fragmentation pattern with those described in the literature ${ }^{8,37,38}$. The assignment of hydroxyl-group at C-23 position in hydroxytomatine was based on NMR of isolated hydroxytomatine compound from GAME31-Ox lines as described below (refer "Hydroxytomatine purification for NMR analysis" and "NMR methods" section). Protein extracts obtained from empty pET28 vector-transformed E. coli BL21 (DE3) cells were used in control reactions.

\section{E. coli expression and in vitro assays for GAME enzymes. ScGAME31-M6,} ScGAME31-8380-1, ScGAME32-M6, ScGAME32-8380-1-1, ScGAME32-8380-1-2, and ScGAME32-like genes from the respective S. chacoense accession (M6 and 8380-1) and GAME31 and GAME32-like gene from cultivated potato ( $c v$. Desiree) were separately cloned into the pET28b vector and expressed in E. coli BL21 (DE3) cells. Bacterial cells were grown in $\mathrm{LB}$ medium at $37^{\circ} \mathrm{C}$. When cultures reached $A_{600}=0.6$, protein expression was induced with $200 \mu \mathrm{M}$ of IPTG at $15^{\circ} \mathrm{C}$, for $24 \mathrm{~h}$. Bacterial cells were lysed by sonication in $50 \mathrm{mM}$ Tris- $\mathrm{HCl} \mathrm{pH} 7.5,500 \mathrm{mM} \mathrm{NaCl}, 10 \%$ glycerol, and protease inhibitor cocktail (Calbiochem). Soluble proteins were purified on Ni-NTA agarose beads (Adar Biotech) and eluted with $500 \mathrm{mM}$ imidazole in buffer containing $50 \mathrm{mM} \mathrm{NaH} \mathrm{PO}_{4}(\mathrm{pH} 7.5)$ and $300 \mathrm{mM} \mathrm{NaCl}$. The whole-cell extract and the eluted fractions were analyzed by sodium dodecyl sulfate-polyacrylamide gel electrophoresis stained with InstatBlue. Assays with the recombinant GAME31, GAME32, and GAME32-like enzymes purified from E. coli cells using SAA/SGA substrates were performed under standard assay conditions, as described above. Enzyme assay products were analyzed by UPLC-qTOF-MS using standard (long gradient, $40 \mathrm{~min}$ ) conditions as follows: from 100 to $72 \%$ phase A over 22 min, from 72 to $0 \%$ phase A over $14 \mathrm{~min}$, then held at $100 \%$ phase B for $2 \mathrm{~min}$; and then returned to the initial conditions (100\% phase A) within $0.5 \mathrm{~min}$ and conditioning at $100 \%$ phase $\mathrm{A}$ for $1.5 \mathrm{~min}$, unless stated otherwise. Other LC-MS parameters are same as described above. Enzyme assay products were identified based on accurate mass-derived elemental composition and MS-MS fragmentation pattern with those described earlier $8,10,28,38,42$. The control reaction was performed using protein extracts from E. coli cells transformed with empty pET28 vector.

Recombinant 2-ODD34 protein expression and in vitro assays. Cloning, E. coli expression, and purification of Sc2-ODD34 (from M6 accession) and two 2ODD34 from cultivated potato ( $c v$. Desiree) were performed as described above for other GAME genes. In vitro recombinant 2-ODD34 enzyme $(5 \mu \mathrm{g})$ assay with SAA/SGA substrates along with control reaction were carried out under standard assay conditions, as described above.

Phylogenetic analysis. GAME31, GAME32, GAME32-like, 2-ODD34, and its homologous sequences from Solanum plants were identified using the BLASTP program (https://blast.ncbi.nlm.nih.gov/Blast.cgi). Sequence alignments were performed using ClustalOmega ${ }^{43}$. The Maximum Likelihood tree was inferred in MEGA6 using 1000 bootstrap replications ${ }^{44}$. Evolutionary distances are in units of number of amino acid substitutions per site. All positions containing gaps and missing data were eliminated. Amino acid sequences used in the phylogenetic analysis are provided in Supplementary Data 3.

Hydroxytomatine purification for NMR analysis. Methanolic extracts from $\sim 10 \mathrm{~g}$ GAME31-Ox transgenic plant leaves (\#1, \#2 are two independent GAME31-Ox transgenic lines, and from each transgenic line, $\sim 5 \mathrm{~g}$ leaves were collected) were evaporated to dryness and re-dissolved in $1000 \mu \mathrm{l} 80 \%$ methanol. The system consisted of an Agilent 1290 Infinity II UPLC system equipped with a quaternary pump, auto sampler, diode array detector, a Bruker/Spark Prospekt II LC-SPE system (Spark), and Impact HD UHR-QqTOF mass spectrometer (Bruker) connected via a Bruker NMR MS Interface (BNMI-HP) ${ }^{45}$. MS spectra, in positive mode, were acquired between $\mathrm{m} / \mathrm{z} 50$ and 1700. The calibration was done with a $10-\mathrm{mM}$ sodium trifluoroacetate (Sigma-Aldrich) automatically, which is introduced at the beginning and the end of each chromatographic run. Separation was done on a XBridge LC column (BEH C18, $5 \mu \mathrm{m}$ particle size, and $250 \mathrm{~mm} \times$ $4.6 \mathrm{~mm}$; Waters). The chromatographic conditions were as follows: a flow rate of $0.9 \mathrm{ml} \mathrm{min}^{-1}$ starting with a solvent composition of $87 \%$ A (5\% acetonitrile $(\mathrm{ACN})+0.1 \%$ formic acid $(\mathrm{FA}))$ and $13 \% \mathrm{~B}(100 \% \mathrm{ACN}+0.1 \% \mathrm{FA})$ with a linear gradient to $85 \% \mathrm{~A}$ at $30 \mathrm{~min}$, followed by another linear gradient to $100 \% \mathrm{~B}$ at $32 \mathrm{~min}, 100 \% \mathrm{~B}$ held for $6 \mathrm{~min}$ followed by linear gradient to $87 \% \mathrm{~A}$ at 38.5 , and held for $1.5 \mathrm{~min}$ for equilibration. Hydroxytomatine was collected on solid-phase extraction (SPE) cartridges in pre-set time windows and trapping was triggered by intensity threshold (hydroxytomatine $(\mathrm{m} / z$ 594.4-main fragment, threshold 510,000 , time window $19-24 \mathrm{~min}$ ). For this trapping process, a makeup flow of $2.5 \mathrm{ml} \mathrm{min}-1$ water was added to the eluent before it passed through the SPE cartridges in order to increase the retention of analytes on the cartridges. For the trapping, $10 \mathrm{~mm} \times 2 \mathrm{~mm} \mathrm{SPE}$ cartridges filled with GP resin were used. Each cartridge was loaded five times with the same compound (i.e. hydroxytomatine), and 5-10 cartridges were used for trapping hydroxytomatine. Prior to NMR measurements, SPE cartridges were dried with a stream of nitrogen, and the fraction from each cartridge was eluted with a total of $150 \mu$ l deuterated methanol.
The sample was eluted into 96-well plate. Eluents containing same compound were pooled, dried under stream of nitrogen, freeze-dried, resuspended in $200 \mu \mathrm{l}$ of $\mathrm{D}_{2} \mathrm{O}$, and freeze-dried again to remove traces of $\mathrm{H}_{2} \mathrm{O}$. Dry compounds were dissolved in $60 \mu \mathrm{l} 90 \% \mathrm{MeOD}-\mathrm{d} 410 \% \mathrm{D}_{2} \mathrm{O}$ with $0.01 \%$ addition of 3-propionic-2,2,3,3-d4 acid sodium salt (that was used as an internal chemical shift reference for ${ }^{1} \mathrm{H}$ and ${ }^{13} \mathrm{C}$ spectra) and transferred to a $1.7-\mathrm{mm}$ NMR test tube.

NMR methods. NMR spectra were recorded on a Bruker AVANCE NEO-600 NMR spectrometer equipped with a 5-mm TCI-xyz CryoProbe equipped with shielded gradient coils. All spectra were acquired at $293 \mathrm{~K}$. NMR data of hydroxytomatine were recorded on $5 \mathrm{~mm}$ CryoProbe (using a special NMR spinner turbine to hold the $1.7 \mathrm{~mm}$ test tube in a $5-\mathrm{mm}$ probe). ${ }^{1} \mathrm{H}$ and ${ }^{13} \mathrm{C}$ chemical shift assignment was based on different 1D and 2D NMR techniques (double quantum filtered correlation spectroscopy (DQF-COSY), total correlated spectroscopy (TOCSY), rotating-frame Overhauser spectroscopy, heteronuclear single quantum coherence (HSQC), heteronuclear multiple bond correlation (HMBC), and HSQC-TOCSY) all using pulsed field gradient selection, combining HMBC-derived information (Supplementary Table 1) with DQF-COSY and TOCSY correlations. No nuclear Overhauser effect interaction was observed for H-23 (using rotating Overhauser effect mixing times 100-250 ms), therefore it was difficult to determine the configuration of H-25. NMR spectra for hydroxytomatine is provided in Supplementary Figs. 33-40.

Reporting summary. Further information on research design is available in the Nature Research Reporting Summary linked to this article.

\section{Data availability}

Data supporting the findings of this work are available within the paper and its Supplementary Information files. A reporting summary for this article is available as a Supplementary Information file. The datasets generated and analyzed during the current study are available from the corresponding author upon request. The source data underlying Figs. 2c, 2d, 3a, 3b, and 4a, and Supplementary Figs 2b, 3b, 4b, 5b, 6b, 15, 16, 18 , and 22 are provided as a Source Data File.

Received: 18 May 2019; Accepted: 6 October 2019; Published online: 14 November 2019

\section{References}

1. Friedman, M., McDonald, G. \& Filadelfi-keszi, M. Potato glycoalkaloids: chemistry analysis safety and plant physiology. Crit. Rev. Plant Sci. 16, 55-132 (1997).

2. Friedman, M. Tomato glycoalkaloids: role in the plant and in the diet. J. Agric. Food Chem. 50, 5751-5780 (2002)

3. Friedman, M. Potato glycoalkaloids and metabolites: roles in the plant and in the diet. J. Agric. Food Chem. 54, 8655-8681 (2006).

4. Milner, S. E. et al. Bioactivities of glycoalkaloids and their aglycones from Solanum species. J. Agric. Food Chem. 59, 3454-3484 (2011).

5. Cárdenas, P. D. et al. The bitter side of the nightshades: genomics drives discovery in Solanaceae steroidal alkaloid metabolism. Phytochemistry 113, 24-32 (2015).

6. Sonawane, P. D. et al. Short-chain dehydrogenase/reductase governs steroidal specialized metabolites structural diversity and toxicity in the genus Solanum. Proc. Natl Acad. Sci. USA 115, E5419-E5428 (2018).

7. Rick, C., Uhlig, J. \& Jones, D. High a-tomatine content in ripe fruit of Andean Lycopersicon esculentum var. Cerasiforme: developmental and genetic aspects. Proc. Natl Acad. Sci. USA 91, 12877-12881 (1994).

8. Itkin, M. et al. GLYCOALKALOID METABOLISM1 is required for steroidal alkaloid glycosylation and prevention of phytotoxicity in tomato. Plant Cell 23, 4507-4525 (2011).

9. Mintz-Oron, S. et al. Gene expression and metabolism in tomato fruit surface tissues. Plant Physiol. 147, 823-851 (2008).

10. Itkin, M. et al. Biosynthesis of antinutritional alkaloids in Solanaceous crops is mediated by clustered genes. Science 341, 175-179 (2013).

11. Sinden, S., Sanford, L., Cantelo, W. \& Deahl, K. Bioassays of segregating plants: a stratgey for studying chemical defenses. J. Chem. Ecol. 14, 1941-1950 (1988).

12. Sturckow, B. \& Low, I. The effects of some Solanum glycoalkaloids on the colorado potato beetle. Entomol. Exp. Appl. 4, 133-142 (1961).

13. Sinden, S., Stanford, L. \& Deahl, K. Segregation of leptine glycoalkaloids in Solanum chacoense bitter. J. Agric. Food Chem. 34, 371-377 (1986).

14. Sinden, S., Sanford, L., Cantelo, W. \& Deahl, K. Leptine glycoalkaloids and resistance to the Colorado potato beetle (coleoptera: chrysomelidae) in Solanum chacoense. Environ. Entomol. 15, 1057-1062 (1986).

15. Sinden, S. L., Sanford, L. L. \& Osman, S. F. Glycoalkaloids and resistance to the Colorado potato beetle in Solanum chacoense bitter. Am. Potato J. 57, 331-343 (1980). 
16. Yencho., C., Kowalski., S., Kennedy, G. \& Sanford, L. Segregation of leptine glycoalkaloids and resistance to Colorado potato beetle (Leptinotarsa decemlineata (Say)) in F2 Solanum tuberosum $(4 \mathrm{x}) \times$ S. chacoense $(4 \mathrm{x})$ potato progenies. Am. J. Potato Res. 77, 167-178 (2000).

17. Rangarajan, A., Miller, A. \& Veilleux, R. Leptine glycoalkaloids reduce feeding by Colorado potato beetle in diploid Solanum sp. hybrids. J. Am. Soc. Hortic. Sci. 125, 689-693 (2000).

18. Kowalski, S., Domek, J., Deahl, K. \& Sanford, L. Performance of Colorado potato beetle larvae, Leptinotarsa decemlineata (Say), reared on synthetic diets supplemented with Solanum glycoalkaloids. Am. J. Potato Res. 76, 305-312 (1999).

19. Bouarte-Medina, T. et al. Identification of molecular markers associated with leptine in reciprocal backcross families of diploid potato. Theor. Appl. Genet. 105, 1010-1018 (2002).

20. Ronning, C. M. et al. Identification of molecular markers associated with leptine production in a population of Solanum chacoense bitter. Theor. Appl. Genet. 98, 39-46 (1999).

21. Hutvagner, G. et al. Molecular markers associated with leptinine production are located on chromosome 1 in Solanum chacoense. Theor. Appl. Genet. 102, 1065-1071 (2001).

22. Sagredo, B., Lafta, A., Casper, H. \& Lorenzen, J. Mapping of the genes associated with leptine content of tetraploid potato. Theor. Appl. Genet. 114, 131-142 (2006).

23. Ofner, I., Lashbrooke, J., Pleban, T., Aharoni, A. \& Zamir, D. Solanum pennellii backcross inbred lines (BILs) link small genomic bins with tomato traits. Plant J. 87, 151-160 (2016).

24. Schilmiller, A. et al. Mass spectrometry screening reveals widespread diversity in trichome specialized metabolites of tomato chromosomal substitution lines. Plant J. 62, 391-403 (2010).

25. Farrow, S. \& Facchini, P. Functional diversity of 2-oxoglutarate/Fe(II)dependent dioxygenases in plant metabolism. Front. Plant Sci. 5, 524 (2014).

26. Cárdenas, P. D. et al. GAME9 regulates the biosynthesis of steroidal alkaloids and upstream isoprenoids in the plant mevalonate pathway. Nat. Commun. 7, 10654 (2016).

27. Chitwood, D. H. et al. A quantitative genetic basis for leaf morphology in a set of precisely defined tomato introgression lines. Plant Cell 25, 2465-2481 (2013).

28. Mweetwa, A. et al. Steroidal glycoalkaloids in Solanum chacoense. Phytochemistry 75, 32-40 (2012).

29. Leisner, C. et al. Genome sequence of M6, a diploid inbred clone of the highglycoalkaloid-producing tuber-bearing potato species Solanum chacoense, reveals residual heterozygosity. Plant J. 94, 562-570 (2018).

30. Pandeya, S. C., Sarat Babu, G. V. \& Bhatt, A. B. Dynamics of solasodine accumulation in developing berries of S. sysimbrifollium. Planta Med. 42, 409-411 (1981).

31. Telek, L., Delphin, H. \& Cabanillas, E. Solanum mammosum as a source of solasdine in the lowland tropics. Econ. Bot. 31, 120-128 (1977)

32. Eltayeb, E., Al-Ansari, A. \& Roddick, J. Changes in the steroidal alkaloid solasodine during development of Solanum nigrum and Solanum incanum. Phytochemistry 46, 489-494 (1997).

33. Zhang, J. et al. Full crop protection from an insect pest by expression of long double-stranded RNAs in plastids. Science 347, 991-994 (2015).

34. Eshed, Y. \& Zamir, D. An introgression line population of Lycopersicon pennellii in the cultivated tomato enables the identification and fine mapping of yield-associated QTL. Genetics 141, 1147-1162 (1995).

35. Karimi, M., Inzé, D. \& Depicker, A. GATEWAYTM vectors for Agrobacterium mediated plant transformation. Trends Plant Sci. 7, 193-195 (2002).

36. Sarrion-Perdigones, A. et al. GoldenBraid 2.0: a comprehensive DNA assembly framework for plant synthetic biology. Plant Physiol. 162, 1618-1631 (2013).

37. Schwahn, K., de Souza, Perez, Fernie, L., Tohge, A. R. \& Metabolomicsassisted, T. refinement of the pathways of steroidal glycoalkaloid biosynthesis in the tomato clade. J. Integr. Plant Biol. 56, 864-875 (2014).

38. Heinig, U. \& Aharoni, A. Analysis of steroidal alkaloids and saponins in Solanaceae plant extracts using UPLC-qTOF mass spectrometry. Methods Mol. Biol. 1153, 171-185 (2014).

39. Expósito-Rodríguez, M., Borges, A. A., Borges-Pérez, A. \& Pérez, J. A. Selection of internal control genes for quantitative real-time RT-PCR studies during tomato development process. BMC Plant Biol. 8, 131-142 (2008).

40. Unger, T., Jacobovitch, Y., Dantes, A., Bernheim, R. \& Peleg, Y. Applications of the Restriction Free (RF) cloning procedure for molecular manipulations and protein expression. J. Struct. Biol. 172, 34-44 (2010).
41. Kawai, Y., Ono, E. \& Mizutani, M. Evolution and diversity of the 2oxoglutarate-dependent dioxygenase superfamily in plants. Plant J. $\mathbf{7 8}$, 328-343 (2014)

42. Iijima, Y. et al. Steroidal glycoalkaloid profiling and structures of glycoalkaloids in wild tomato fruit. Phytochemistry 95, 145-157 (2013).

43. Sievers, F. et al. Fast scalable generation of high-quality protein multiple sequence alignments using Clustal Omega. Mol. Syst. Biol. 7, 539 (2011).

44. Tamura, K., Stecher, G., Peterson, D., Filipski, A. \& Kumar, S. MEGA6: molecular evolutionary genetics analysis version 6.0. Mol. Biol. Evol. 30, 2725-2729 (2013)

45. Khakimov, B., Tseng, L. H., Godejohann, M., Bak, S. \& Engelsen, S. B. Screening for triterpenoid saponins in plants using hyphenated analytical platforms. Molecules 21, E1614 (2016).

\section{Acknowledgements}

A.A. is the incumbent of the Peter J. Cohn Professorial Chair. We thank the Adelis Foundation, Leona M. and Harry B. Helmsley Charitable Trust, Jeanne and Joseph Nissim Foundation for Life Sciences, Tom and Sondra Rykoff Family Foundation Research, and the Raymond Burton Plant Genome Research Fund for supporting the A.A. laboratory activity. The work was supported by the Israel Science Foundation (ISF Grant No. 1805/15) and European Research Council (ERC; SAMIT-FP7) personal grants to A.A. The research in the A.A. laboratory was supported by the European Union Seventh Framework Program FP7/2007-2013 under grant agreement no. 613692-TriForC. P.D.C. thanks Becas Chile Program (CONICYT, Chile) for PhD financial support. D.Z. was funded by the European Union's H2020 Research and Innovation Program grant \# 677379 (G2P-SOL).

\section{Author contributions}

P.D.C. and P.D.S. designed and performed the research and wrote the article. U.H. and A.J. contributed to data analysis. S.P., B.A., M.P., Y.K., D.W., and Am G. assisted with the generation of transgenic plants. I.O., E.V., D.Z., and J.S. performed the bioinformatics analysis. I.R., As G. and S.M. assisted with metabolomics data analysis and operated the LC-MS. T.U. and O.D. assisted in the protein purification. T.S. performed and analyzed NMR experiments. S.B., P.D.S., and A.A. designed the research and wrote the article.

\section{Competing interests}

The authors declare no competing interests.

\section{Additional information}

Supplementary information is available for this paper at https://doi.org/10.1038/s41467 019-13211-4.

Correspondence and requests for materials should be addressed to P.D.S. or A.A.

Peer review information Nature Communications thanks the anonymous reviewers for their contribution to the peer review of this work.

Reprints and permission information is available at http://www.nature.com/reprints

Publisher's note Springer Nature remains neutral with regard to jurisdictional claims in published maps and institutional affiliations.

Open Access This article is licensed under a Creative Commons Attribution 4.0 International License, which permits use, sharing, adaptation, distribution and reproduction in any medium or format, as long as you give appropriate credit to the original author(s) and the source, provide a link to the Creative Commons license, and indicate if changes were made. The images or other third party material in this article are included in the article's Creative Commons license, unless indicated otherwise in a credit line to the material. If material is not included in the article's Creative Commons license and your intended use is not permitted by statutory regulation or exceeds the permitted use, you will need to obtain permission directly from the copyright holder. To view a copy of this license, visit http://creativecommons.org/ licenses/by/4.0/

(C) The Author(s) 2019 